\title{
RADIATION EFFECT ON TRANSIENT NATURAL CONVECTION IN VENTILATED ROOFS
}

\author{
Vincenzo Bianco ${ }^{*}$, Alessandra Diana ${ }^{*}$, , Oronzio Manca ${ }^{* *}$ and Sergio Nardini** \\ *Dipartimento di Ingegneria Meccanica, Energetica, Gestionale e dei Trasporti, Università degli Studi \\ di Genova, Genova (GE), Italy \\ *** Dipartimento di Ingegneria Industriale e dell'Informazione, Università degli Studi della Campania \\ Luigi Vanvitelli, Aversa (CE), Italy \\ ${ }^{\S}$ Email: dialex.ad@gmail.com
}

\begin{abstract}
This paper illustrates a numerical investigation on a prototypal ventilated roof for residential use, under summer and winter conditions. The roof is modeled as a single flap, due to its geometric and thermal symmetry, and it is analyzed as two-dimensional, in air flow, thanks to the commercial code Ansys-Fluent. The governing equations are given in terms of $\mathrm{k}-\varepsilon$ turbulence model taking into account the radiation effect inside the channel. The analysis is performed in order to evaluate thermofluidodynamic behaviours of the ventilated roof, in transient regime with radiative heat transfer presence, as a function of the solar radiation applied on the top wall of the ventilated roof. The discrete transfer radiation model (DTRM) is chosen. Typical summer and winter conditions with heat transfer from the channel top wall toward the external ambient are examined. The bottom wall of the ventilated channel is simulated as isothermal, considering optimal temperature values for the internal ambient in summer and winter regimes.

Results are given in terms of temperature and pressure distributions, air velocity and temperature profiles along longitudinal and cross sections of the ventilated layer, in order to estimate the differences between the various conditions. Ventilated roof configuration results significant to reach optimal thermal and fluid dynamic conditions in summer and winter regimes. In summer period, when the effect of solar radiation is more evident thanks to the convective effect within the channel, temperature values are higher and the effect of the ventilated channel is significative to reach comfort conditions. In winter, the effect of the ventilated layer is very important to reach optimal thermal and hygrometric conditions.
\end{abstract}

\section{NOMENCLATURE}

$b$ : channel width, [m]

$C_{1}, C_{2}, C_{\mu}$ : empirical constants in the k- $\varepsilon$ turbulence model

$D$ : Extra term in Turbulence kinetic energy equation

$E$ : Roughness parameter

$f_{1}, f_{2}, f_{\mu}$ : Wall damping function

$G_{b}$ : Production of turbulent kinetic energy due to buoyancy

$G_{k}$ : Production of turbulent kinetic energy due to mean velocity gradient

$h$ : hipped roof height, [m]

$k$ : kinetic energy of turbulence 
$k_{\text {ext }}$ : total thermal conductance of the upper layers of ventilated roof (between the channel and the external ambient, $\left[\mathrm{W} / \mathrm{m}^{2} \mathrm{~K}\right]$

$k_{f}, k_{s}$ : fluid and solid thermal conductivity, [W/K m]

$L$ : channel length, $[\mathrm{m}]$

$L_{x}, L_{y}:$ reservoir dimensions, [m]

$T_{\text {avg: }}$ average value of the temperature in the exit section of the channel, [K]

$T_{\text {havg: }}$ : average value of the temperature on the top wall of the ventilated channel, $[\mathrm{K}]$

$T_{i}$ : Room temperature, [K]

$T_{e}$ : Cavity temperature, $[\mathrm{K}]$

$T_{\max }$ : maximum value of the temperature in the channel.

$T_{\infty}$ : Flow temperature, $[\mathrm{K}]$

$T_{s}$ : Channel wall (surface) temperature, $[\mathrm{K}]$

$T_{o}$ : Environment temperature, $[\mathrm{K}]$

$T_{S}$ : Summer condition temperature, $[\mathrm{K}]$

$T_{W}$ : Winter condition temperature, $[\mathrm{K}]$

$v_{\text {avg: }}$ average value of the velocity in the ventilated channel, $[\mathrm{m} / \mathrm{s}]$

$v_{\max }$ : maximum value of the velocity in the ventilated channel, $[\mathrm{m} / \mathrm{s}]$

$X, Y, Z$ : Cartesian coordinates

$\beta$ : Coefficient of thermal expansion, $\left[\mathrm{K}^{-1}\right]$

$\varepsilon$ : Rate of dissipation of the kinetic energy

$\theta$ : Roof inclination, $\left[{ }^{\circ}\right]$

$\lambda$ : Thermal conductivity, $\left[\mathrm{W} \mathrm{m} \mathrm{m}^{-1} \cdot \mathrm{K}^{-1}\right.$ ]

\section{INTRODUCTION}

Some of the most important requirements for building performance are energy saving and recovering and they are pursued developing new strategies for the reduction of energy consumption, due to the thermal energy transmitted through buildings envelopes. A ventilated roof has a good configuration for energy purposes, in order to respect the European Directive priority regarding the reduction of the energy consumptions due to the heat flux transmitted through the envelope of residential and commercial buildings. Comfort conditions should be thermally and achieved saving energy to reduce the costs, the row materials (not renewable resources) and the environmental pollution. In this work, Mediterranean regions are considered, because they are characterized by a high level of solar radiation and ventilation allows to the cooling load during summer period and contributes to the reduction of the energy needs of buildings. The most important advantage of natural ventilation is the reduction of the heat fluxes transmitted by the structures exposed to the solar radiation, thanks to the combined effect of the surfaces shading and of the heat removed by the air flow rate within the ventilated air gap. There are many roof configuration and the ventilated roof is particularly advantageous for a scrupulous design of a building. In winter period, a ventilated roof helps to contain heat losses, and in summer period, it helps reducing the solar heat gain and improving the indoor thermal comfort. The typical configuration of a ventilated roof is set up by an air cavity between two layers of solid materials (Figure 1). The pressure gap living between the inlet and the outlet of the cavity, and the temperature gap living between the external and the inner air, activate a bouyancy force and it makes the air flow rising inside the cavity, so part of the stored heat is carried out of the roof and the heat transmission towards building's interior is reduced.

Ozdeniz [2015] tested 14 different roof contructions, under different regimes, to investigate the risk of condensation and the thermal comfort for the users. The best performance was shown by the roof with thermal insulation. Lee [2009] esperimentally inestigated airflow and temperature distribution in the cavity of a ventilated roof as functions of the slope of the roof, the intensity of solar radiation, the size and the shape of the cavity and panel profiles. Villi [2009] and Dimuodi [2006] analyzed he effects of construction parameters in summer and winter conditions and ventilated roof performances were more remarkable than a conventional roof. Manca [2014] carried out a 
numerical investigation on a prototypal ventilated roof for residential use thanks to a 2D symmetric model. The analysis evaluated the thermic and the fluidodynamic behavior of the roof considering different geometric parameters. Diana [2016] evaluated the thermofluidodynamic effect of the solar radiation applied on the top wall of a ventilated roof in summer and winter conditions.

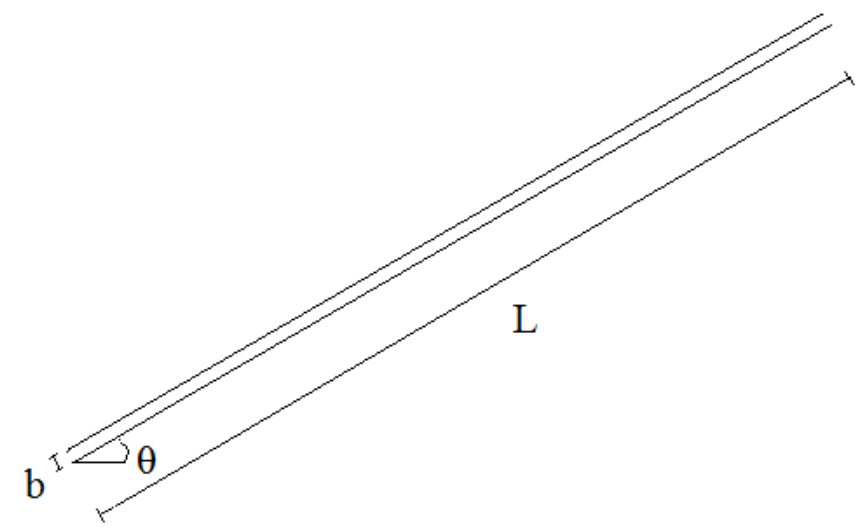

Figure 1. Ventilated channel.

Tong [2014] developed a theoretical model considering radiation and convection in a roof cavity thanks to a computational fluid-dynamics (CFD) analisis. A valid agreement between experimentally measures and numerically simulations for airflow velocity and temperature in the cavity was found. Biwole [2008] investigated radiation, convection and conduction heat transfer in double-skin roofs thanks to a $2 \mathrm{D}$ numerical simulation. A system formed by a metallic screen placed on a sheet metal roof was analyzed. The screen reflected a large amount of solar radiation and natural convection in the cavity banished the residual heat. The system's efficiency abated power costs for air conditioning in tropical and arid regions. Dimoudi [2006] compared a full scale ventilated roof to a conventional roof under real climatic conditions, considering air gap height and the utilization or not of a radiant barrier. Ventilated components have the best performance during the summer period. Gagliano [2012] studied the effect of ventilation of building structures, verifing that it decreased the cooling load in territories with an high level of solar radiation. The advantage was particularly evident during summer period. Piva [2016] used realistic data sets for solar radiation, temperature and wind to simulate summer conditions at different times of the day and a batten space in pitched roofs resulted a good solution for diminishing the solar heat gain in summer period. Li [2016] studied that the effect of the ventilated layer of the roof was strong on the themperature delay of the roof, but it was weak on the delay time. Banionis [2012] showed that installing radiant barriers with low emissivity coefficient into the roof construction reduced the additional radiative heat flow caused by the interior surface of the roofs coating into the building.

This paper illustrates a numerical investigation on a prototypal ventilated roof for residential use, under summer and winter conditions. The roof is modelled as a single flap, due to its geometric and thermal symmetry, and it is analyzed as two-dimensional, in air flow, thanks to the commercial code AnsysFluent. The governing equations are given in terms of k- $\varepsilon$ turbulence model taking into account the radiation effect inside the channel. The analysis is performed in order to evaluate thermofluidodynamic behaviours of the ventilated roof, in transient regime with radiative heat transfer presence, as a function of the solar radiation applied on the top wall of the ventilated roof. The net radiative heat flux from the surface is computed as the sum of the reflected fraction of the incident and emitted heat fluxes. The discrete transfer radiation model (DTRM) is chosen. Typical summer and winter conditions with heat transfer from the channel top wall toward the external ambient are examined.

Results are given in terms of temperature and pressure distributions, air velocity and temperature profiles along longitudinal and cross sections of the ventilated layer, in order to estimate the differences 
between the various conditions. Ventilated roof configuration results significant to reach optimal thermal and fluid dynamic conditions in summer and winter regimes.

\section{MATHEMATICAL MODEL}

A two-dimensional physical domain is investigated. Since the configuration of the domain is geometrically and thermally symmetry, a single side of the ventilated roof is considered, as shown in Figure 1. The ventilated roof used for building insulation is composed by layers of several materials combined conveniently. The numerical model used in simulations is an inclined channel, with the upper line simulating the properties of all layers above the ventilated cavity, and the bottom line simulating the properties of all layers under the cavity.

As shown in Figure 2, the computational domain has finite dimensions, since the roof is placed in an infinite medium. It is composed by the ventilated channel, a storage located at the inlet of the channel and a storage located at the outlet of the channel. The outlet storage dimensions depend on the height, $h$, and the form of the ridge, as shown in the particular. The two storages allow to know what happens in the region where the thermal disturbance is caused by the heat applied on the upper wall of the ventilated channel to simulate the free-stream condition of the flow.

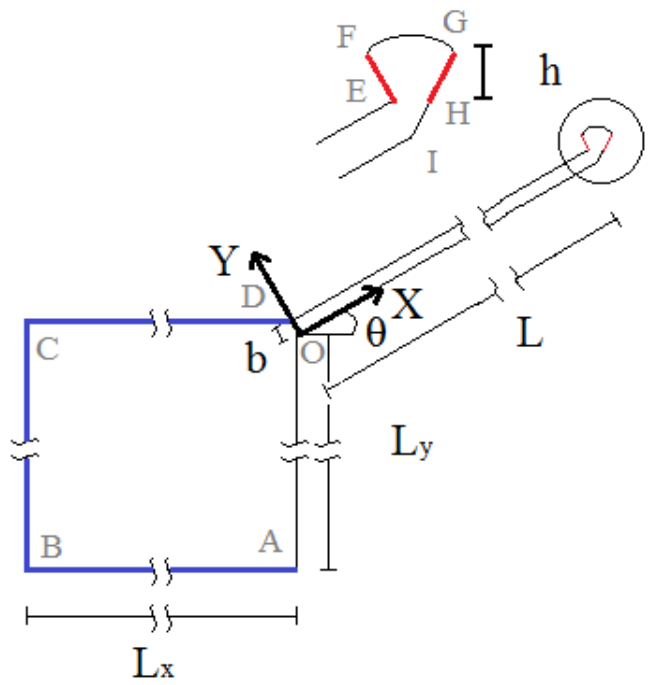

Figure 2. Computational domain.

The ventilated channel has a length $L$, an inclination $\theta$, a width $b$. Inlet storage dimensions are $L_{x}$ and $L_{y}$ and they are equal to the average height of a floor. Outlet storage dimensions depend on the exit section of the channel and the height of the ridge $h$.

Table 1 describes the geometric values of the elements composing the model:

Table 1

Geometric Parameter Values of the Model

\begin{tabular}{|l|l|}
\hline $\mathrm{L}[\mathrm{m}]$ & 6.00 \\
\hline $\mathrm{B}[\mathrm{m}]$ & 0.10 \\
\hline $\mathrm{h}[\mathrm{m}]$ & 0.10 \\
\hline$\theta\left[{ }^{\circ}\right]$ & 30 \\
\hline $\mathrm{L}_{\mathrm{x}}[\mathrm{m}]$ & 3.00 \\
\hline $\mathrm{L}_{\mathrm{y}}[\mathrm{m}]$ & 3.00 \\
\hline
\end{tabular}

The governing equations for the simulation are written as: mass conservation, momentum equation and energy conservation. They are coupled, non-linear and partial differential equations and their numerical solutions are obtained using the commercial code Ansys-Fluent 12.2 by the finite volume method. 
Conservation of mass:

$$
\frac{\partial \rho}{\partial t}+\rho \bar{\nabla} \cdot \bar{V}=0
$$

Conservation of x-momentum:

$$
\rho \frac{D u}{D t}=\rho f_{x}-\frac{\partial p}{\partial x}+\frac{\partial \tau_{x x}}{\partial x}+\frac{\partial \tau_{y x}}{\partial y}+\frac{\partial \tau_{z x}}{\partial z}
$$

Conservation of y-momentum:

$$
\rho \frac{D v}{D t}=\rho f_{y}-\frac{\partial p}{\partial y}+\frac{\partial \tau_{x y}}{\partial x}+\frac{\partial \tau_{y y}}{\partial y}+\frac{\partial \tau_{z y}}{\partial z}
$$

Conservation of z-momentum:

$$
\rho \frac{D w}{D t}=\rho f_{z}-\frac{\partial p}{\partial z}+\frac{\partial \tau_{x z}}{\partial x}+\frac{\partial \tau_{y z}}{\partial y}+\frac{\partial \tau_{z z}}{\partial z}
$$

Conservation of Energy:

$$
\rho c_{p} \frac{D T}{D t}=k \nabla^{2} T+\mu_{t} \Phi+u^{\prime \prime \prime}
$$

The turbulent dynamic viscosity is calculated as follows:

$$
\mu_{t}=\rho \cdot C_{\mu} \cdot f_{\mu} \cdot\left(\frac{k^{2}}{\varepsilon}\right)
$$

Turbulence kinetic energy (k-equation)

$$
\begin{aligned}
& \frac{\partial}{\partial x}(\rho \bar{u} k)+\frac{\partial}{\partial y}(\rho \bar{v} k)+\frac{\partial}{\partial z}(\rho \bar{w} k)=\frac{\partial}{\partial x}\left[\left(\mu+\frac{\mu_{t}}{\sigma_{k}}\right) \frac{\partial k}{\partial x}\right]+ \\
& \frac{\partial}{\partial y}\left[\left(\mu+\frac{\mu_{t}}{\sigma_{k}}\right) \frac{\partial k}{\partial y}\right]+\frac{\partial}{\partial z}\left[\left(\mu+\frac{\mu_{t}}{\sigma_{k}}\right) \frac{\partial k}{\partial z}\right]+ \\
& G_{k}+G_{b}-\rho \varepsilon-D
\end{aligned}
$$

Turbulence dissipation ( $\varepsilon$-equation):

$$
\begin{aligned}
& \frac{\partial}{\partial x}(\rho \overline{u \varepsilon})+\frac{\partial}{\partial y}(\rho \overline{v \varepsilon})+\frac{\partial}{\partial z}(\rho \bar{w} \varepsilon)=\frac{\partial}{\partial x}\left[\left(\mu+\frac{\mu_{t}}{\sigma_{\varepsilon}}\right) \frac{\partial \varepsilon}{\partial x}\right] \\
& +\frac{\partial}{\partial y}\left[\left(\mu+\frac{\mu_{t}}{\sigma_{\varepsilon}}\right) \frac{\partial \varepsilon}{\partial y}\right]+\frac{\partial}{\partial z}\left[\left(\mu+\frac{\mu_{t}}{\sigma_{\varepsilon}}\right) \frac{\partial \varepsilon}{\partial z}\right] \\
& +C_{\varepsilon 1} f_{1} \frac{\varepsilon}{k}\left(G_{k}+G_{\varepsilon 3} G_{b}\right)-C_{\varepsilon 2} f_{2} \frac{\varepsilon^{2}}{k}+E
\end{aligned}
$$

In the k-Equation (7), the first term is the kinetic energy transport of turbulence and the second term is transport of $\mathrm{k}$ by diffusion.

In the $\varepsilon$-Equation (8), the first term is the dissipation kinetic energy rate by convection and the second term is the transport of $\varepsilon$ by diffusion. 
$\mathrm{G}_{\mathrm{k}}$ is the rate of generation of turbulent kinetic energy as the result of mean velocity gradients, $\rho \varepsilon$ is the destruction rate of the turbulent kinetic energy and $G_{b}$ is the rate of generation of turbulent kinetic as a result of buoyancy. Furthermore, there are two extra terms, D in k-Equation and E in $\varepsilon$-Equation, to report near wall behavior. Finally, $\mathrm{f}_{1}$ and $\mathrm{f}_{2}$ are the wall damping functions in Equation (8).

The net radiative heat flux from the surface is calculated as the amount of the reflected fraction of the incident and emitted heat fluxes:

$$
\begin{array}{r}
q_{r}(x)=(1-\varepsilon) q_{\text {in }}(x)+\varepsilon \sigma T_{w}^{4}(x) \\
q_{\text {in }}(x)=\int_{s \cdot n>0} I_{\text {in }} \cdot s \cdot n d \Omega
\end{array}
$$

The discrete transfer radiation model (DTRM) was chosen to simulate the radiation. All surfaces are assumed diffuse, therefore the reflection of incident radiation at the surface is isotropic as regards the solid angle. DTRM assumed the approximation that the radiation going away from a surface element, in a certain range of solid angles, can be seen as a single ray. Also, the scattering effect is negligible and all the walls are considered gray. The convergence criteria for the residuals of the velocity components is 10-5and 10-8 for the residuals of the energy is 10-8.

The flow in the channel is two-dimensional. The regime is transient and turbulent. Viscous dissipations are assumed negligible. Thermophysical properties are considered constant with temperature, except for density (Boussinesq approximation), which induces buoyancy forces. Air is the working fluid and its thermophysical properties are calculated at the operative temperature.

In this work, the analysis simulates two regimes: summer condition and winter condition. In summer, the operative temperature is equal to $300 \mathrm{~K}$. To simulate the optimal ambient condition in summer, the bottom wall of the ventilated channel is simulated as isothermal, with $\mathrm{T}=298 \mathrm{~K}$. A uniform heat flux is applied on the top wall of the channel and its values depends on the day hours and significative heat flux values are reported from 9:00 to 18:00 in a typical summer day.

In winter, the operative temperature is equal to $275 \mathrm{~K}$. To simulate the optimal ambient condition in winter, the bottom wall of the ventilated channel is simulated as isothermal, with $\mathrm{T}=293 \mathrm{~K}$. A uniform heat flux is applied on the top wall of the channel and its values depends on the day hours and significative heat flux values are reported from 9:00 to 16:00 in a typical winter day.

Heat flux values are obtained thanks to the database PVGIS-CMSAF for summer and winter regimes. Furthermore, on the bottom wall of the ventilated channel, it is applied the heat transfer coefficient $h$ equal to $5 \mathrm{~W} / \mathrm{m}^{2} \mathrm{~K}$ to simulate the properties of layers under the cavity. On the top wall of the cavity, it is applied the heat transfer coefficient $\mathrm{h}$ equal to $10 \mathrm{~W} / \mathrm{m}^{2} \mathrm{~K}$ to simulate the properties of structure layers above the cavity [Çengel 2011].

The Boundary Conditions imposed for the analysis are reported in Table 2 for the fluid domain and in Table 3 for the solid domain.

Table 2

Boundary Conditions for the Fluid Domain

\begin{tabular}{|l|c|c|c|}
\hline Wall & $\boldsymbol{u}$ & $\boldsymbol{v}$ & $\boldsymbol{T}$ \\
\hline $\begin{array}{l}\mathrm{AB} \\
\text { And } \\
\mathrm{CD}\end{array}$ & $\frac{\partial u}{\partial x}=0$ & $\frac{\partial v}{\partial y}=0$ & $\mathrm{~T}=\mathrm{T}_{0}$ \\
\hline $\mathrm{BC}$ & $\frac{\partial u}{\partial y}=0$ & $\frac{\partial v}{\partial x}=0$ & $\mathrm{~T}=\mathrm{T}_{0}$ \\
\hline $\begin{array}{l}\mathrm{EF} \\
\text { And } \\
\text { GH }\end{array}$ & $\frac{\partial u}{\partial n}=0$ & $\frac{\partial v}{\partial n}=0$ & $\left\{\begin{array}{l}u>0 \rightarrow \frac{\partial T}{\partial n}=0 \\
u<0 \rightarrow T=T_{0}\end{array}\right.$ \\
\hline
\end{tabular}


In particular, the Boundary Conditions for reservoirs are important because they simulate the thermal and fluid dynamic behaviors far away the inflow and outflow regions.

Table 3

Boundary Conditions for the Solid Domain

\begin{tabular}{|l|c|}
\hline Wall & $\boldsymbol{T}$ \\
\hline OA & $\frac{\partial T}{\partial n}=0$ \\
\hline FG and HI & $\frac{\partial T}{\partial n}=0$ \\
\hline OI & $T=$ Constant \\
\hline DE & $-k_{s} \frac{\partial T}{\partial n}=k_{\text {ext }}\left(T_{s}-T_{\infty}\right)+\sigma \varepsilon\left(T_{s}^{4}-T_{e}^{4}\right)-\dot{q}$ \\
\hline
\end{tabular}

\section{NUMERICAL SOLUTION}

The geometric model and the mesh of the computational domain are realized thanks to the software Gambit [Gambit Guide 2007]. In particular, creating the mesh, several grids were realized and compared, depending on Richardson's extrapolation equation. On the basis of Richardson's extrapolation equation, it is possible to estimate a reference value of a generic quantity, comparing two successive configurations related to the examined meshes.

The percentage error is evaluated in terms of average Nusselt number, which is related to the upper surface of the cavity. The results are compared for five different grids.

Table 4 reports the number of calculation cells $\mathrm{N}$ and the values of Nusselt Number. Figure 3 shows the percentage error.

Table 4

Percentage error on Nusselt number.

\begin{tabular}{|c|c|c|c|}
\hline Mesh & $\mathrm{N}_{\text {cells }}$ & $\mathrm{Nu}$ & $\%$ ERR \\
\hline 1 & 13651 & 249.67 & 8.98 \\
\hline 2 & 27022 & 257.37 & 5.72 \\
\hline 3 & 42134 & 268.47 & 1.35 \\
\hline 4 & 52057 & 269.16 & 1.09 \\
\hline 5 & 82527 & 269.5 & 0.96 \\
\hline 6 & 150981 & 272.09 & - \\
\hline
\end{tabular}

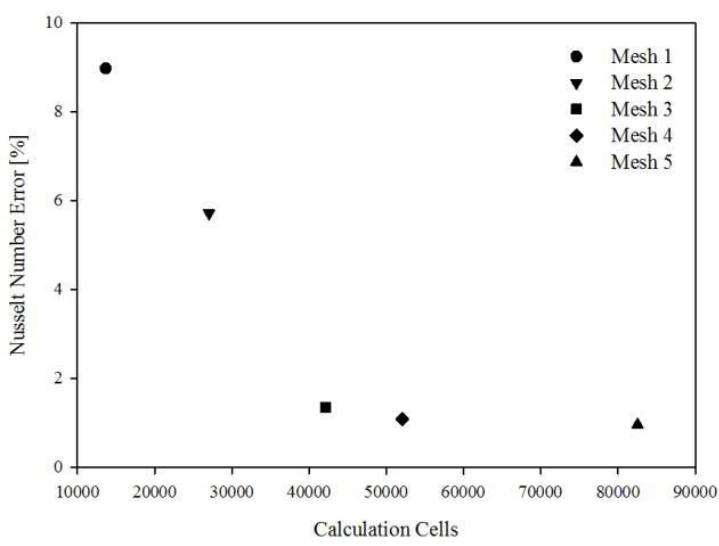

Figure 3: Percentage Nusselt number error. 
The chosen grid counts 52057 calculation cells (Mesh 4) and it represents the optimal compromise between the accuracy of the simulation and the duration of the calculation time.

\section{RESULTS AND DISCUSSION}

The purpose of this study is to analyze the thermal and fluid dynamic behaviors of a ventilated roof in summer and winter conditions. In a typical summer day, the heat flux value is significant from 667 $\mathrm{W} / \mathrm{m}^{2} \mathrm{~K}$ at 9:00 to $85 \mathrm{~W} / \mathrm{m}^{2} \mathrm{~K}$ at 18:00. In a typical winter day, the heat flux value is significant from $310 \mathrm{~W} / \mathrm{m}^{2} \mathrm{~K}$ at 9:00 to $81 \mathrm{~W} / \mathrm{m}^{2} \mathrm{~K}$ at $16: 00$. For brevity, six cases are reported to analyze the seasonal behavior of the ventilated roof: three in summer conditions and three in winter conditions. They are described in Table 5:

Table 5

Analyzed Cases

\begin{tabular}{|l|l|l|c|}
\hline Case & Season & Time & Heat Flux \\
\hline 1 & Summer & $9: 00$ & $\dot{q}_{s}=667 \mathrm{~W} / \mathrm{m}^{2}$ \\
\hline 2 & Summer & $12: 00$ & $\dot{q}_{s}=862 \mathrm{~W} / \mathrm{m}^{2}$ \\
\hline 3 & Summer & $15: 00$ & $\dot{q}_{s}=593 \mathrm{~W} / \mathrm{m}^{2}$ \\
\hline 4 & Winter & $9: 00$ & $\dot{q}_{w}=310 \mathrm{~W} / \mathrm{m}^{2}$ \\
\hline 5 & Winter & $12: 00$ & $\dot{q}_{w}=478 \mathrm{~W} / \mathrm{m}^{2}$ \\
\hline 6 & Winter & $15: 00$ & $\dot{q}_{w}=245 \mathrm{~W} / \mathrm{m}^{2}$ \\
\hline
\end{tabular}

Heat transfer and air flow are influenced by the heat flux applied on the top wall of the cavity. In summer regime, for Case 1, velocity values are higher near the outlet section of the channel because of the air heating, as shown in Figure 4(a), and the maximum value is equal about to 0.88 $\mathrm{m} / \mathrm{s}$. Temperature values grow in the ventilated channel with the distance from the inlet section, reaching the maximum on the top wall of the cavity, as shown in Figure 4(b), and it is equal to 330 $\mathrm{K}$.

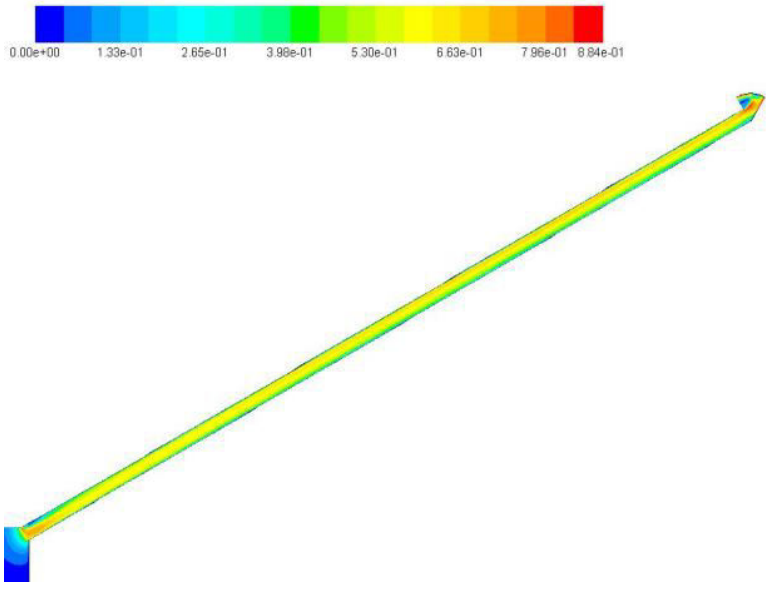

(a) Air velocity field.

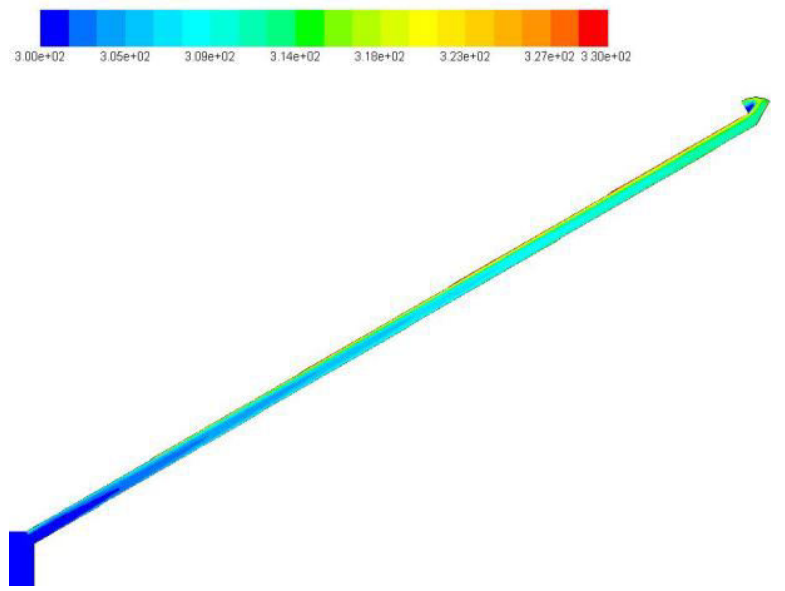

(b) Air temperature field.

Figure 4. Case 1: Air velocity and temperature fields in the ventilated channel.

Figure 5 and Figure 6 show, in particular, the inlet and the outlet sections of the ventilated channel. Velocity stream functions (Figure 5) underline that the fluid reaches the higher velocity values in the zone near the heated wall of the channel. 
Velocity vectors show value increase near the inlet section of the channel in Figure 6(a). In proximity of the ridge, velocity vectors highlight a vortex and the maximum velocity value is obtained, as shown in Figure 6(b).
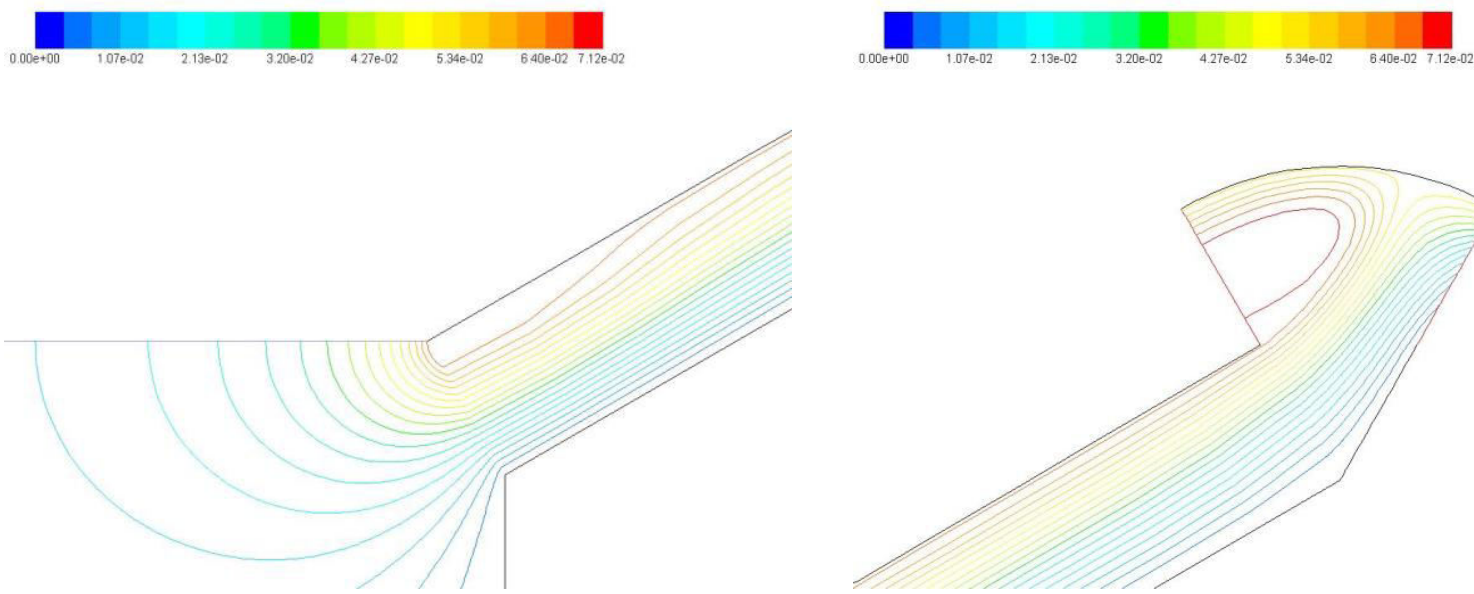

(a) Inlet section.

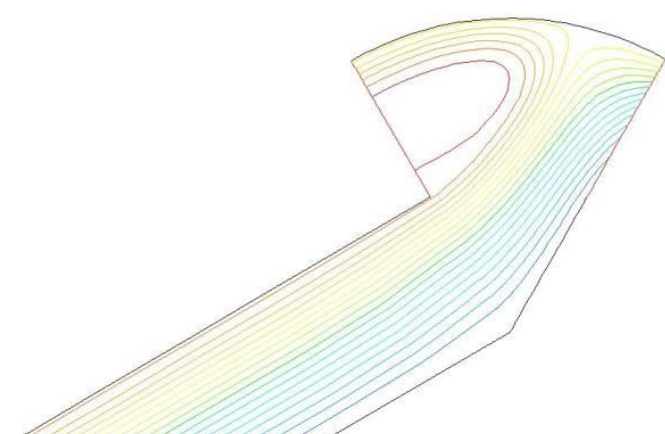

(b) Outlet section.

Figure 5. Case 1: Velocity stream functions at inlet and outlet sections of the channel.
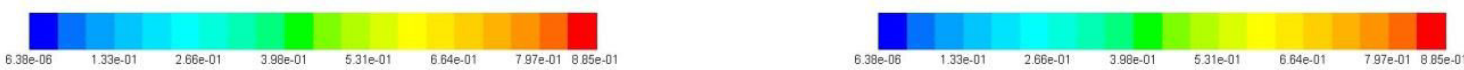

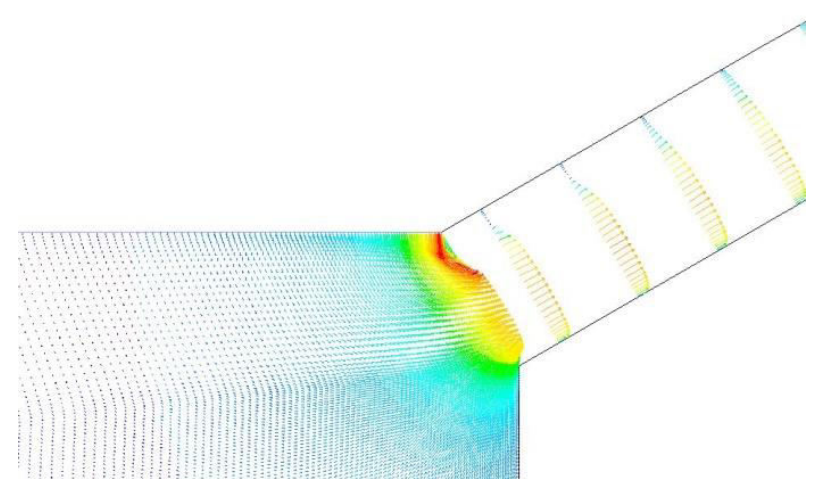

(a) Inlet section.

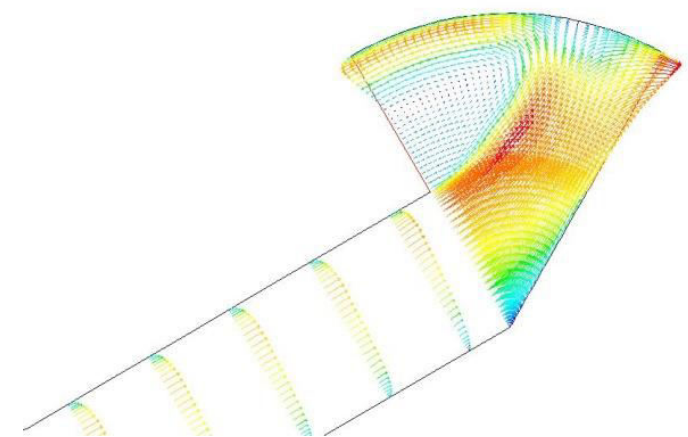

(b) Outlet section.

Figure 6. Case 1: Velocity vectors at inlet and outlet sections of the channel.

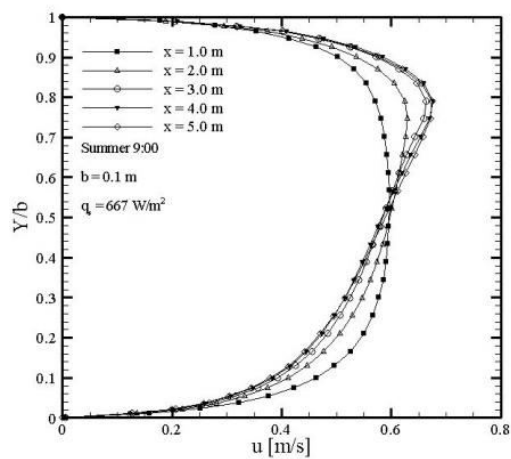

(a) Air velocity profile in cross sections.

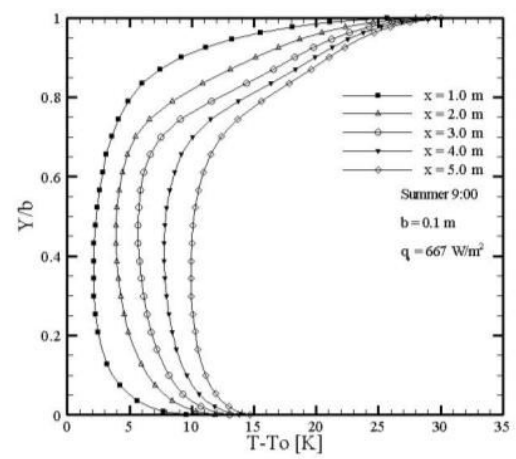

(b) Air temperature profile in cross sections.

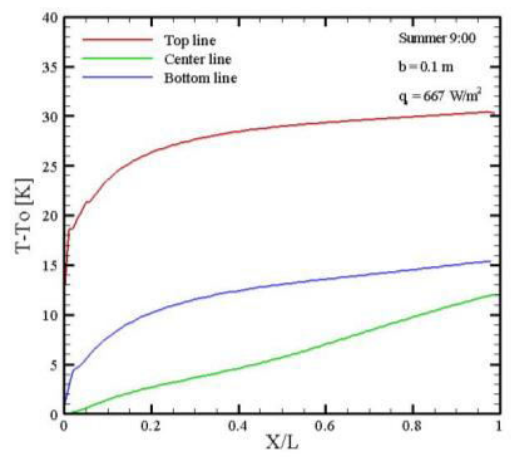

(c) Air temperature profile in the channel.

Figure 7. Case 1: Air velocity and temperature profiles in the ventilated channel. 
Figure 7(a) shows air velocity profiles of five channel cross sections, placed at $1.00 \mathrm{~m}, 2.00 \mathrm{~m}, 3.00$ $\mathrm{m}, 4.00 \mathrm{~m}$ and $5.00 \mathrm{~m}$ from the entrance of the ventilated channel. The effect of the heating is more evident near the hot top wall. The velocity value is maximum at $\mathrm{x}=5.0 \mathrm{~m}$ and it is equal to about $0.67 \mathrm{~m} / \mathrm{s}$.

Figure 7(b) shows air temperature profiles of five channel cross sections, placed at $1.00 \mathrm{~m}, 2.00 \mathrm{~m}$, $3.00 \mathrm{~m}, 4.00 \mathrm{~m}$ and $5.00 \mathrm{~m}$ from the entrance of the ventilated channel. Temperature values are lower in the central zone of the channel, whereas the radiative heat transfer grants the heating of the bottom wall of the channel.

Figure 7(c) shows air temperature profile of three longitudinal direction of the channel: the top wall, the bottom wall and the axis of the channel. All the profiles increase along the channel and for the top and the bottom walls temperature values increase mainly in the lower zone of the channel. In the central zone of the channel, temperature values increase about linearly. The temperature difference between the lower surface and the central section is about $3 \mathrm{~K}$. The temperature difference between the upper surface and the central section is about $18 \mathrm{~K}$. On the top line, the increment of temperature value is about $17 \mathrm{~K}$ near the exit section.

In summer regime, for Case 2, velocity values are higher near the outlet section of the channel because of the air heating, as shown in Figure 8(a), and the maximum value is equal about to 0.99 $\mathrm{m} / \mathrm{s}$. Temperature values grow in the ventilated channel with the distance from the inlet section, reaching the maximum on the top wall of the cavity, as shown in Figure 8(b), and it is equal to 338 $\mathrm{K}$.

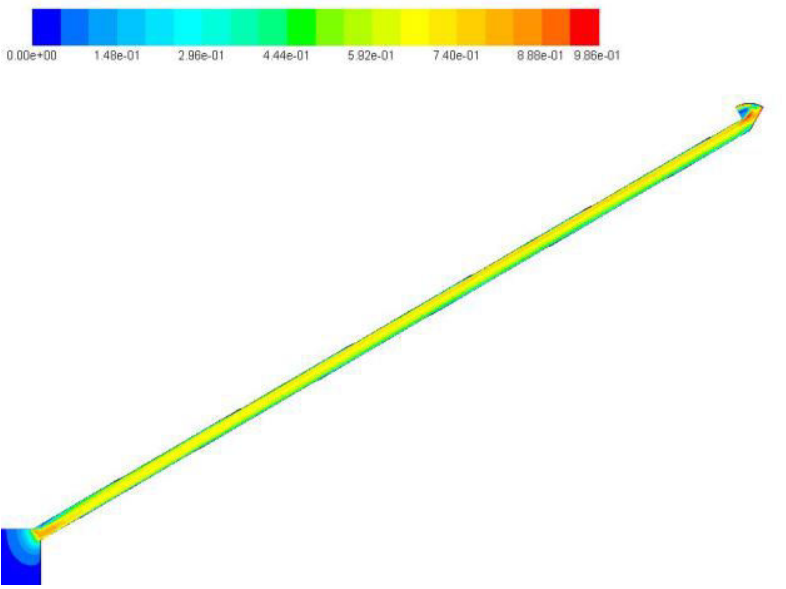

(a) Air velocity field.

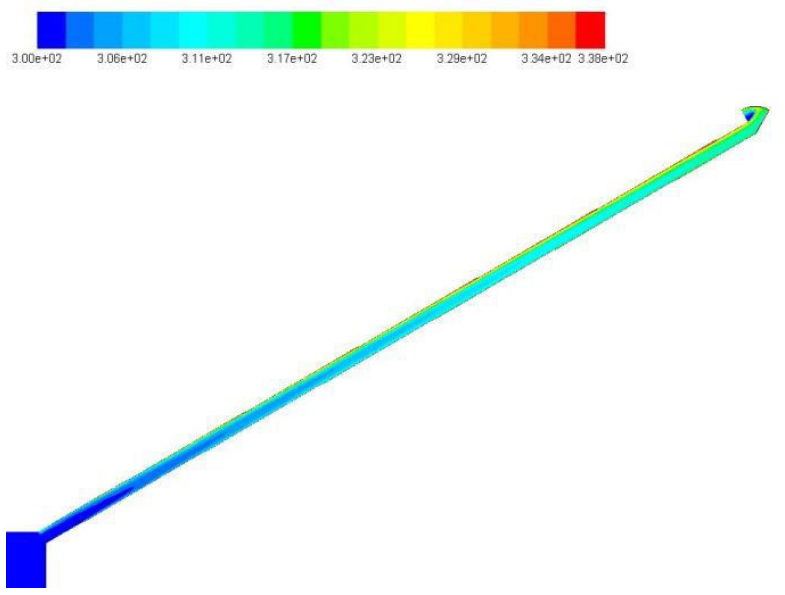

(b) Air temperature field.

Figure 8. Case 2: Air velocity and temperature fields in the ventilated channel.
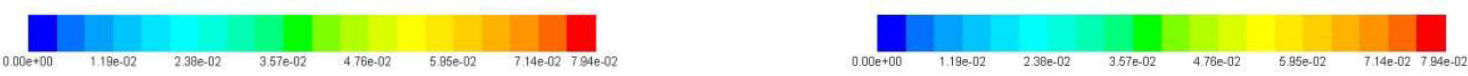

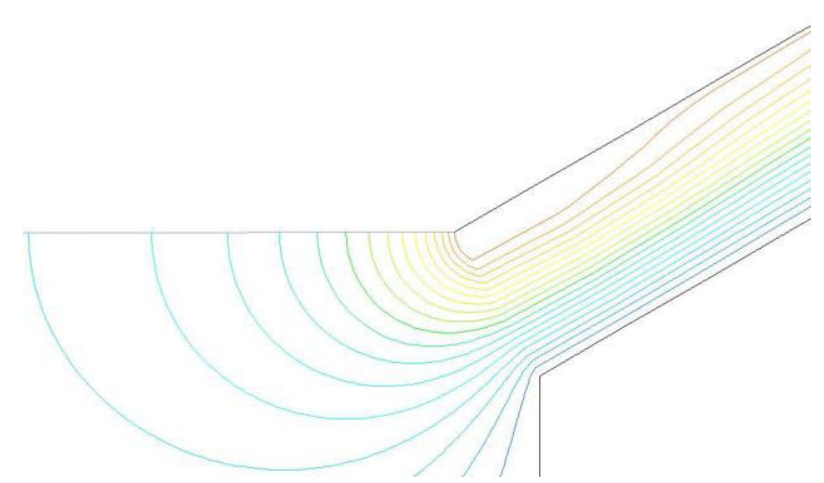

(a) Inlet section.

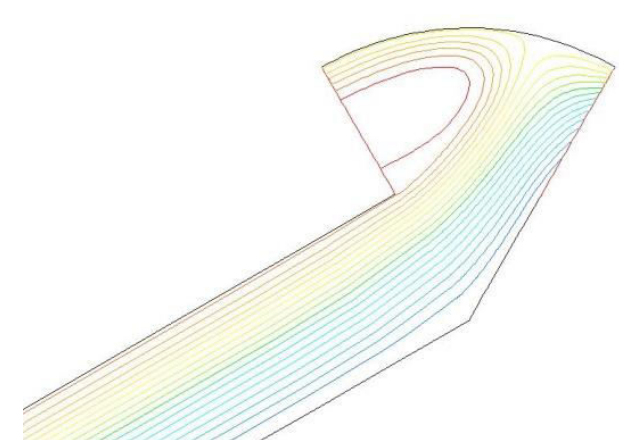

(b) Outlet section. 
Figure 9. Case 2: Velocity stream functions at inlet and outlet sections of the channel.
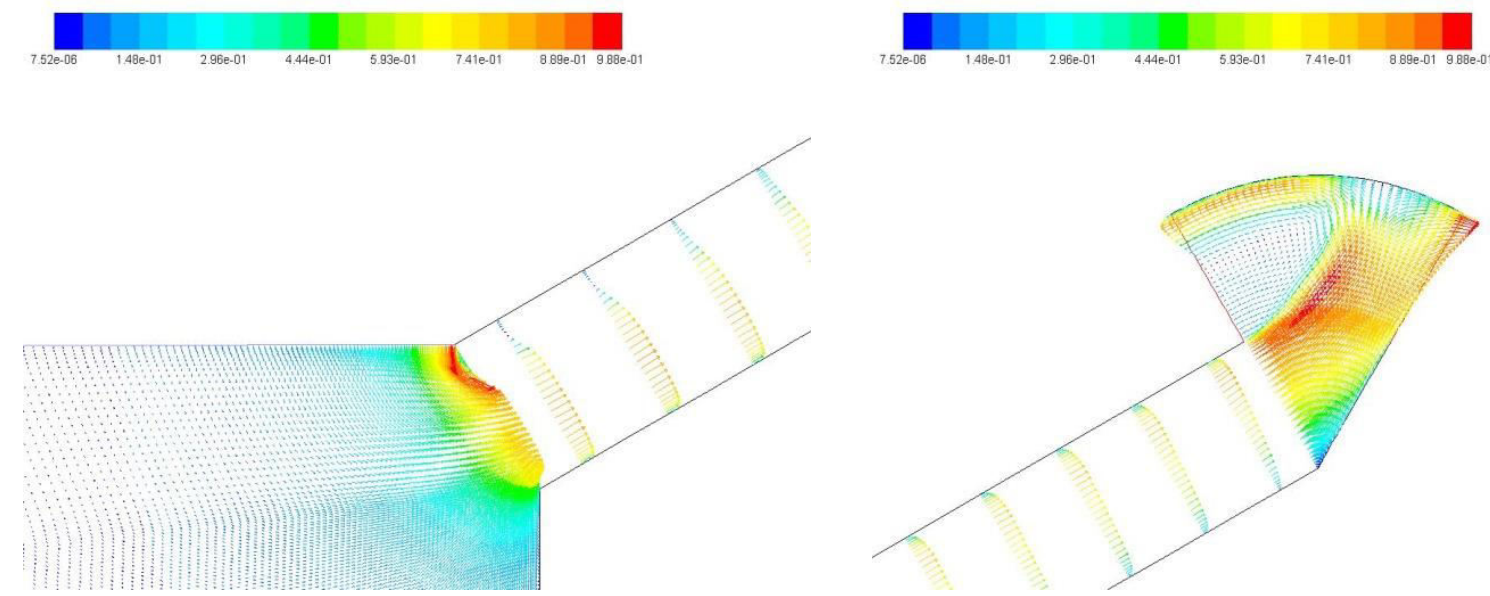

(a) Inlet section.

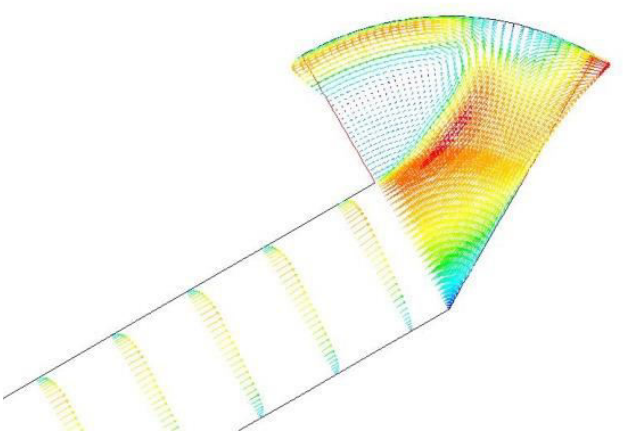

(b) Outlet section.

Figure 10. Case 2: Velocity vectors at inlet and outlet sections of the channel.

Figure 9 and Figure 10 show, in particular, the inlet and the outlet sections of the ventilated channel. Velocity stream functions (Figure 9) underline that the fluid reaches the higher velocity values in the zone near the heated wall of the channel.

Velocity vectors show value increase near the inlet section of the channel in Figure 10(a). In proximity of the ridge, velocity vectors highlight a vortex and the maximum velocity value is obtained, as shown in Figure 10(b).

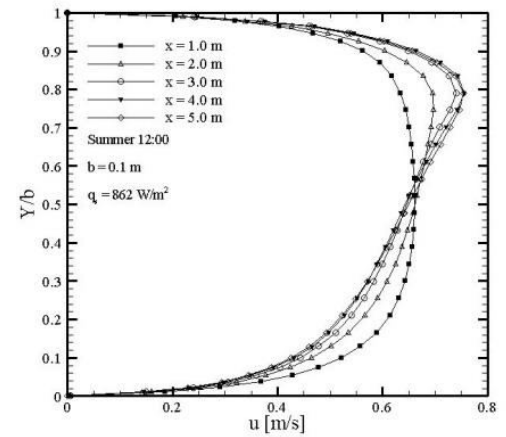

(a) Air velocity profile in cross sections.

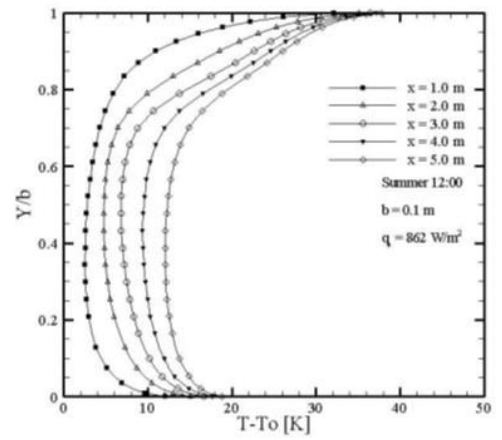

(b) Air temperature profile in cross sections.

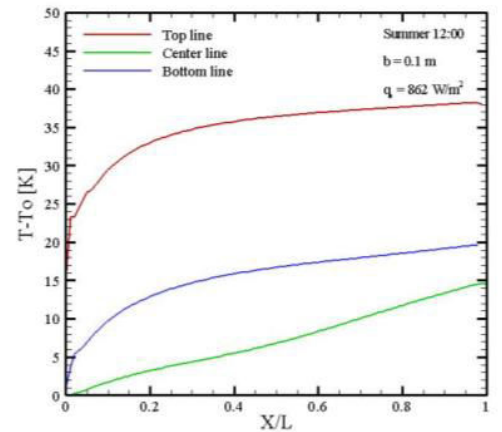

(c) Air temperature profile in the channel.

Figure 11. Case 2: Air velocity and temperature profiles in the ventilated channel.

Figure 11(a) shows air velocity profiles of five channel cross sections, placed at $1.00 \mathrm{~m}, 2.00 \mathrm{~m}$, $3.00 \mathrm{~m}, 4.00 \mathrm{~m}$ and $5.00 \mathrm{~m}$ from the entrance of the ventilated channel. The effect of the heating is more evident near the hot top wall. The velocity value is maximum at $\mathrm{x}=5.0 \mathrm{~m}$ and it is equal to about $0.75 \mathrm{~m} / \mathrm{s}$.

Figure 11(b) shows air temperature profiles of five channel cross sections, placed at $1.00 \mathrm{~m}, 2.00 \mathrm{~m}$, $3.00 \mathrm{~m}, 4.00 \mathrm{~m}$ and $5.00 \mathrm{~m}$ from the entrance of the ventilated channel. Temperature values are lower in the central zone of the channel, whereas the radiative heat transfer grants the heating of the bottom wall of the channel. Values are higher than in Case 1 along all sections.

Figure 11(c) shows air temperature profile of three longitudinal direction of the channel: the top wall, the bottom wall and the axis of the channel. All the profiles increase along the channel and for the top and the bottom walls temperature values increase mainly in the lower zone of the channel. In 
the central zone of the channel, temperature values increase about linearly. The temperature difference between the lower surface and the central section is about $5 \mathrm{~K}$. The temperature difference between the upper surface and the central section is about $33 \mathrm{~K}$. On the top line, the increment of temperature value is about $23 \mathrm{~K}$ near the exit section.

In summer regime, for Case 3, velocity values are higher near the outlet section of the channel because of the air heating, as shown in Figure 12(a), and the maximum value is equal about to 0.84 $\mathrm{m} / \mathrm{s}$. Temperature values grow in the ventilated channel with the distance from the inlet section, reaching the maximum on the top wall of the cavity, as shown in Figure 12(b), and it is equal to 327 $\mathrm{K}$.

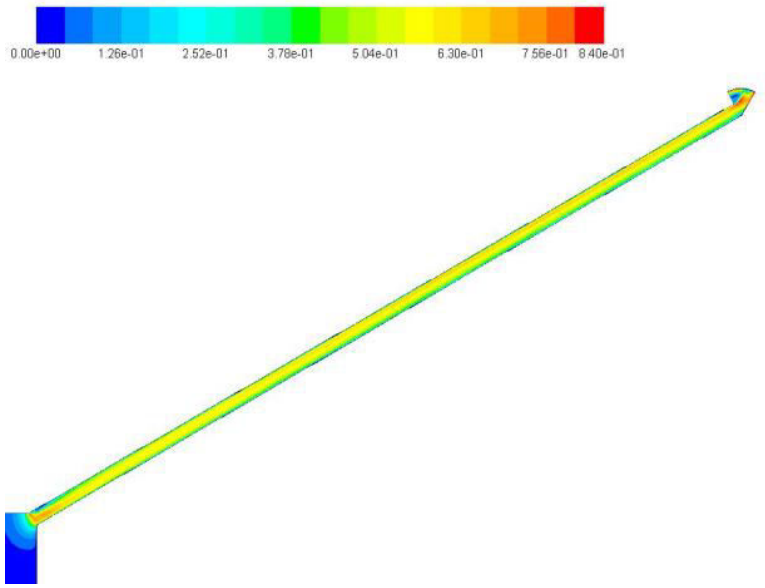

(a) Air velocity field.

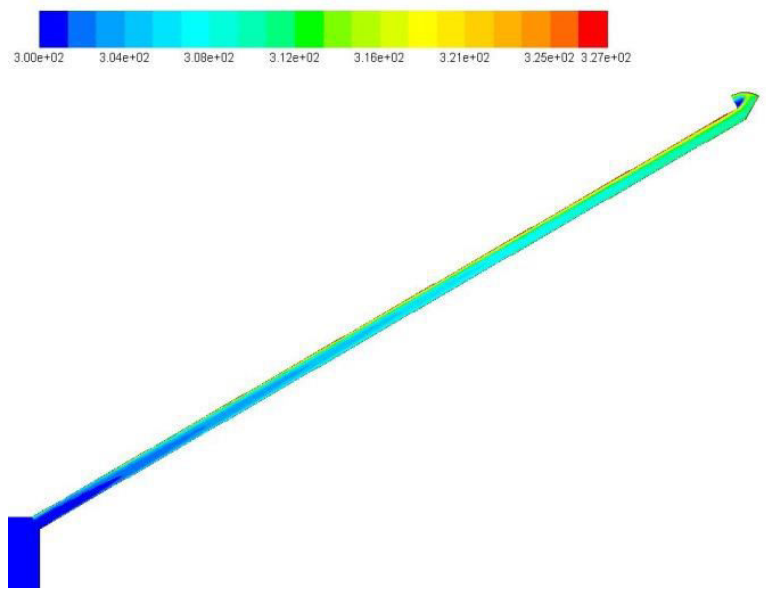

(b) Air temperature field.

Figure 12. Case 3: Air velocity and temperature fields in the ventilated channel.
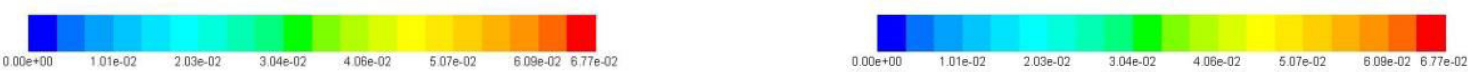

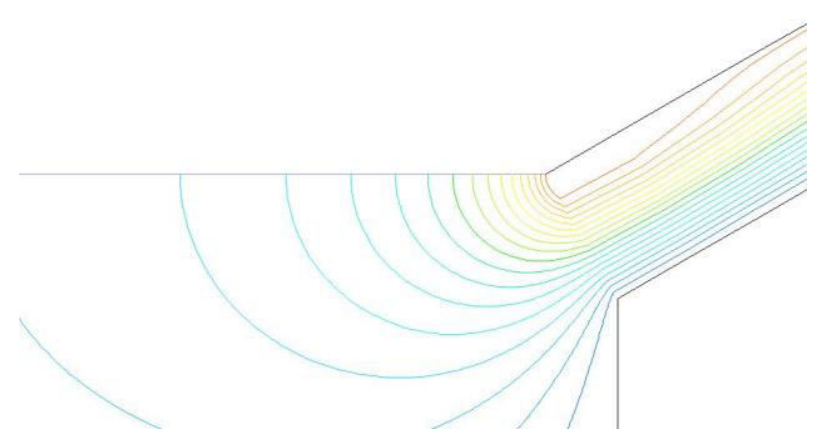

(a) Inlet section.

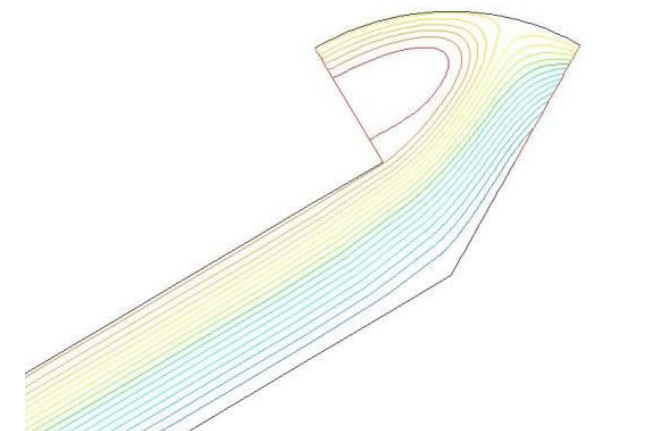

(b) Outlet section.

Figure 13. Case 3: Velocity stream functions at inlet and outlet sections of the channel.

Figure 13 and Figure 14 show, in particular, the inlet and the outlet sections of the ventilated channel. Velocity stream functions (Figure 13) underline that the fluid reaches the higher velocity values in the zone near the heated wall of the channel.

Velocity vectors show value increase near the inlet section of the channel in Figure 14(a). In proximity of the ridge, velocity vectors highlight a vortex and the maximum velocity value is obtained, as shown in Figure 14(b). 

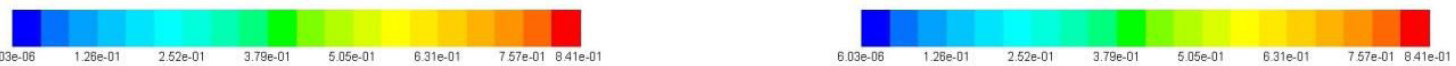

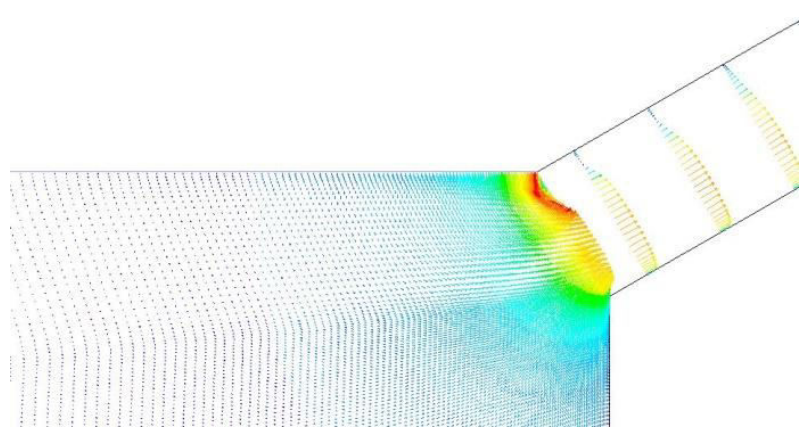

(a) Inlet section.

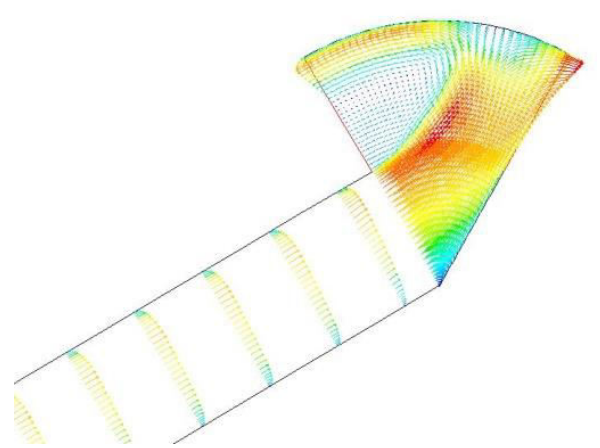

(b) Outlet section.

Figure 14. Case 3: Velocity vectors at inlet and outlet sections of the channel.

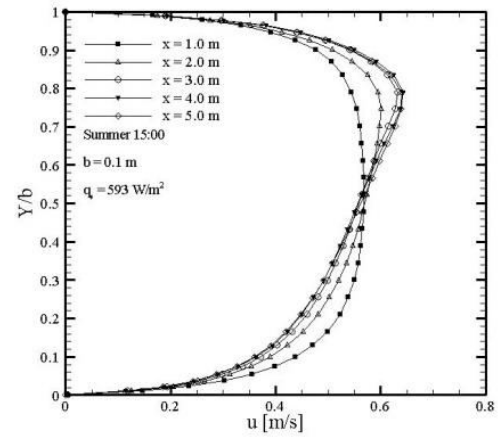

(a) Air velocity profile in cross sections.

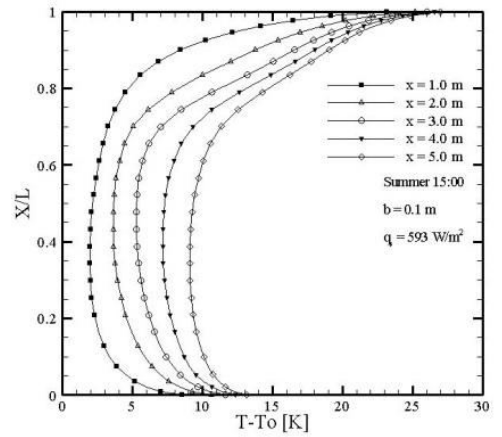

(b) Air temperature profile in cross sections.

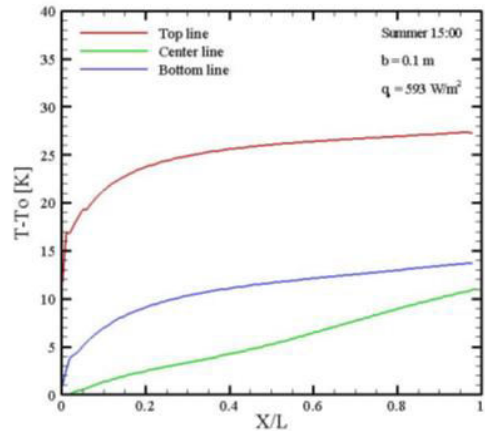

(c) Air temperature profile in the channel.

Figure 15. Case 3: Air velocity and temperature profiles in the ventilated channel.

Figure 15(a) shows air velocity profiles of five channel cross sections, placed at $1.00 \mathrm{~m}, 2.00 \mathrm{~m}$, $3.00 \mathrm{~m}, 4.00 \mathrm{~m}$ and $5.00 \mathrm{~m}$ from the entrance of the ventilated channel. The effect of the heating is more evident near the hot top wall. The velocity value is maximum at $\mathrm{x}=5.0 \mathrm{~m}$ and it is equal to about $0.65 \mathrm{~m} / \mathrm{s}$.

Figure 15(b) shows air temperature profiles of five channel cross sections, placed at $1.00 \mathrm{~m}, 2.00 \mathrm{~m}$, $3.00 \mathrm{~m}, 4.00 \mathrm{~m}$ and $5.00 \mathrm{~m}$ from the entrance of the ventilated channel. Temperature values are lower in the central zone of the channel, whereas the radiative heat transfer grants the heating of the bottom wall of the channel. Values are similar to Case 1.

Figure 15(c) shows air temperature profile of three longitudinal direction of the channel: the top wall, the bottom wall and the axis of the channel. All the profiles increase along the channel and for the top and the bottom walls temperature values increase mainly in the lower zone of the channel. In the central zone of the channel, temperature values increase about linearly. The temperature difference between the lower surface and the central section is less than $3 \mathrm{~K}$. The temperature difference between the upper surface and the central section is about $16 \mathrm{~K}$. On the top line, the increment of temperature value is about $15 \mathrm{~K}$ near the exit section.

In winter regime, air velocity and temperature values show the same trend of summer regime. Temperature grows with the distance from the inlet section and velocity is higher in the outlet reservoir, but values are smaller then in summer regime.

In winter regime, for Case 4, velocity values are higher near the outlet section of the channel because of the air heating, as shown in Figure 16(a), and the maximum value is equal about to 0.79 
$\mathrm{m} / \mathrm{s}$. Temperature values grow in the ventilated channel with the distance from the inlet section, reaching the maximum on the top wall of the cavity, as shown in Figure 16(b), and it is equal to 293 K.
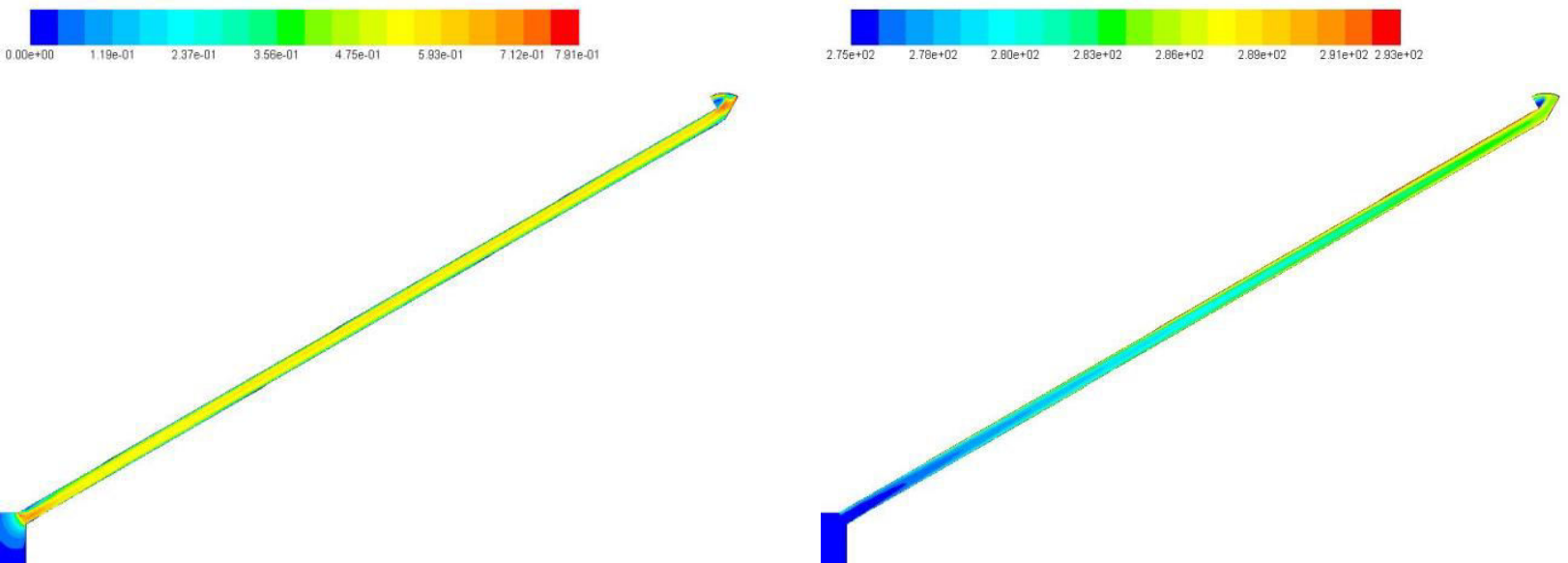

(a) Air velocity field.

(b) Air temperature field.

Figure 16. Case 4: Air velocity and temperature fields in the ventilated channel.
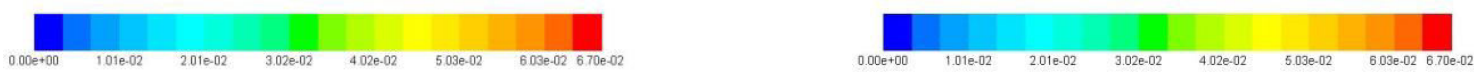

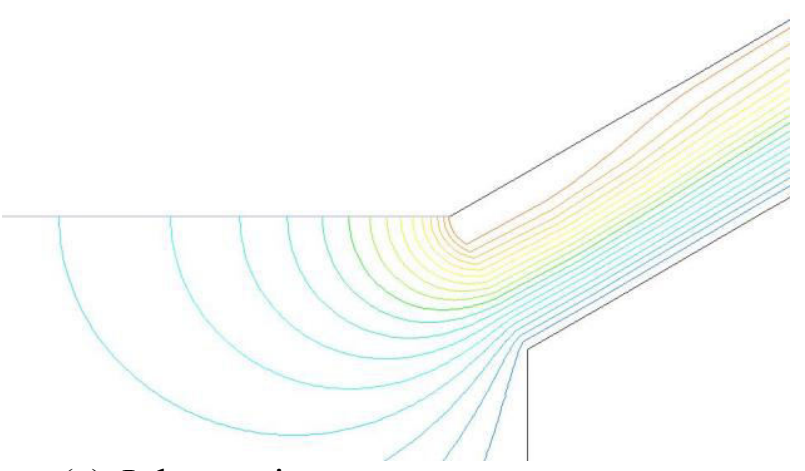

(a) Inlet section.

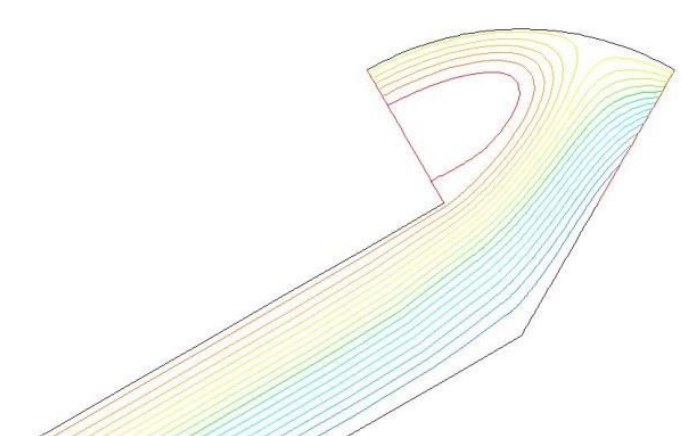

(b) Outlet section.

Figure 17. Case 4: Velocity stream functions at inlet and outlet sections of the channel.
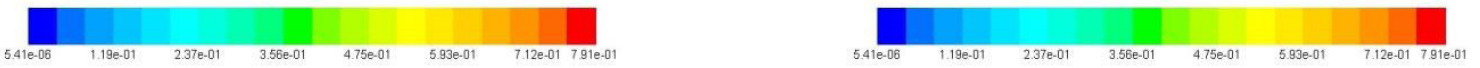

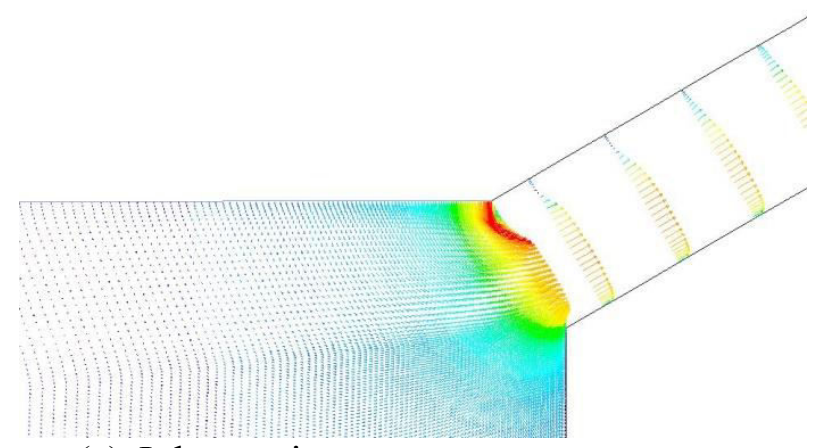

(a) Inlet section.

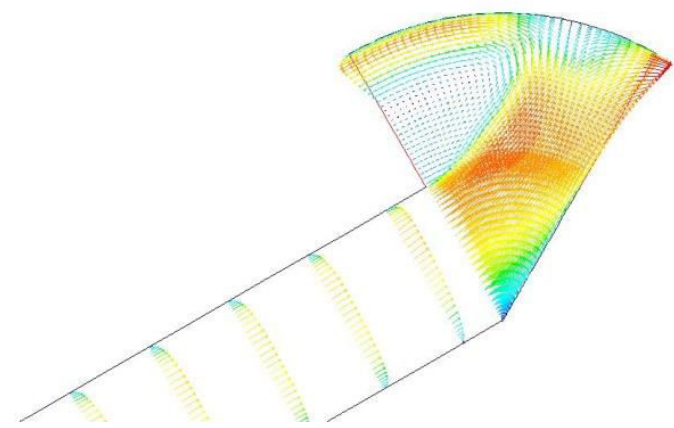

(b) Outlet section.

Figure 18. Case 4: Velocity vectors at inlet and outlet sections of the channel. 
Figure 17 and Figure 18 show, in particular, the inlet and the outlet sections of the ventilated channel. Velocity stream functions (Figure 17) underline that the fluid reaches the higher velocity values in the zone near the heated wall of the channel.

Velocity vectors show value increase near the inlet section of the channel in Figure 18(a). In proximity of the ridge, velocity vectors highlight a vortex and the maximum velocity value is obtained, as shown in Figure 18(b).

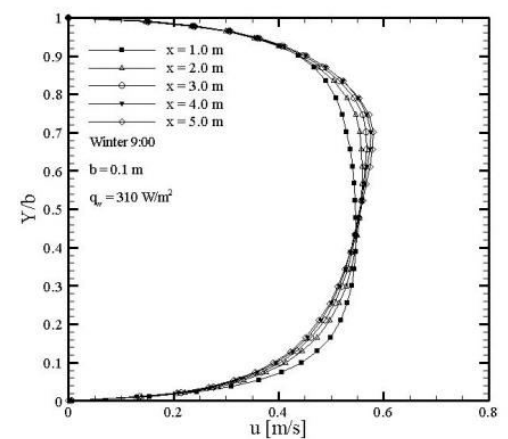

(d) Air velocity profile in cross sections.

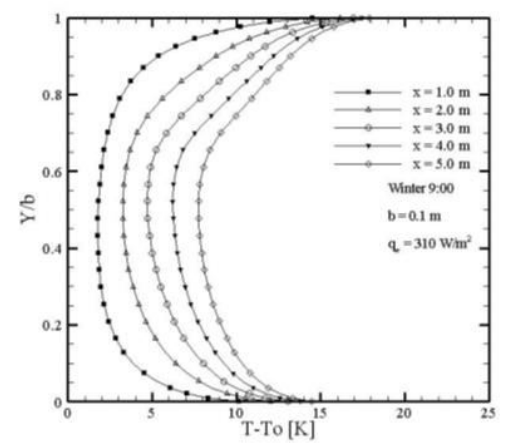

(e) Air temperature profile in cross sections.

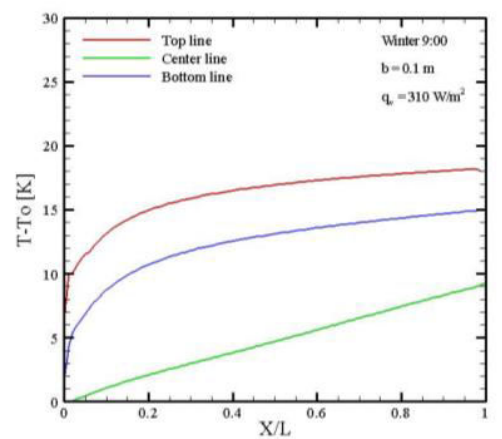

(f) Air temperature profile in the channel.

Figure 19. Case 4: Air velocity and temperature profiles in the ventilated channel.

Figure 19(a) shows air velocity profiles of five channel cross sections, placed at $1.00 \mathrm{~m}, 2.00 \mathrm{~m}$, $3.00 \mathrm{~m}, 4.00 \mathrm{~m}$ and $5.00 \mathrm{~m}$ from the entrance of the ventilated channel. The effect of the heating is more evident near the hot top wall. The velocity value is maximum at $\mathrm{x}=5.0 \mathrm{~m}$ and it is equal to about $0.60 \mathrm{~m} / \mathrm{s}$.

Figure 19(b) shows air temperature profiles of five channel cross sections, placed at $1.00 \mathrm{~m}, 2.00 \mathrm{~m}$, $3.00 \mathrm{~m}, 4.00 \mathrm{~m}$ and $5.00 \mathrm{~m}$ from the entrance of the ventilated channel. Temperature values are lower in the central zone of the channel, whereas the radiative heat transfer grants the heating of the bottom wall of the channel. Near the bottom wall of the channel $(\mathrm{Y} / \mathrm{b}=0)$ values are similar to summer cases, but on the top wall of the channel $(\mathrm{Y} / \mathrm{b}=1)$, temperature values are smaller.

Figure 19(c) shows air temperature profile of three longitudinal direction of the channel: the top wall, the bottom wall and the axis of the channel. All the profiles increase along the channel and for the top and the bottom walls temperature values increase mainly in the lower zone of the channel. In the central zone of the channel, temperature values increase about linearly. The temperature difference between the lower surface and the central section is equal to $6 \mathrm{~K}$. The temperature difference between the upper surface and the central section is about $9 \mathrm{~K}$. On the top line, the increment of temperature value is about $11 \mathrm{~K}$ near the exit section.
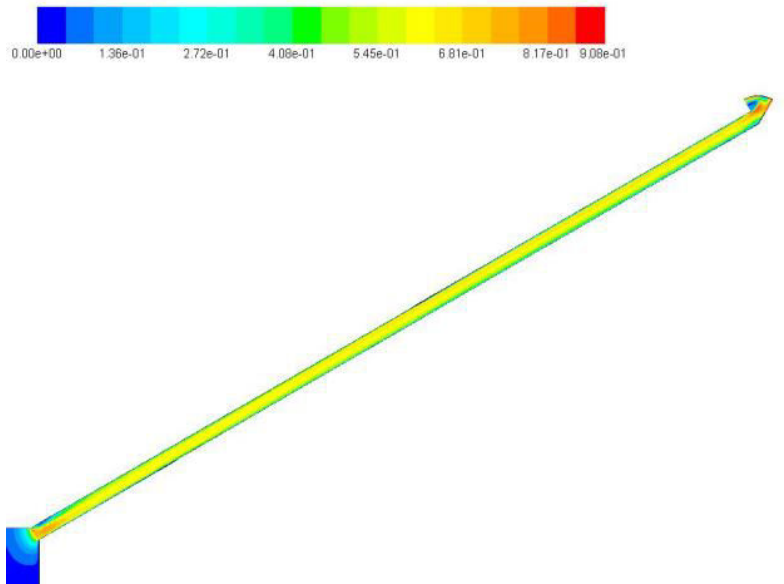

(a) Air velocity field.

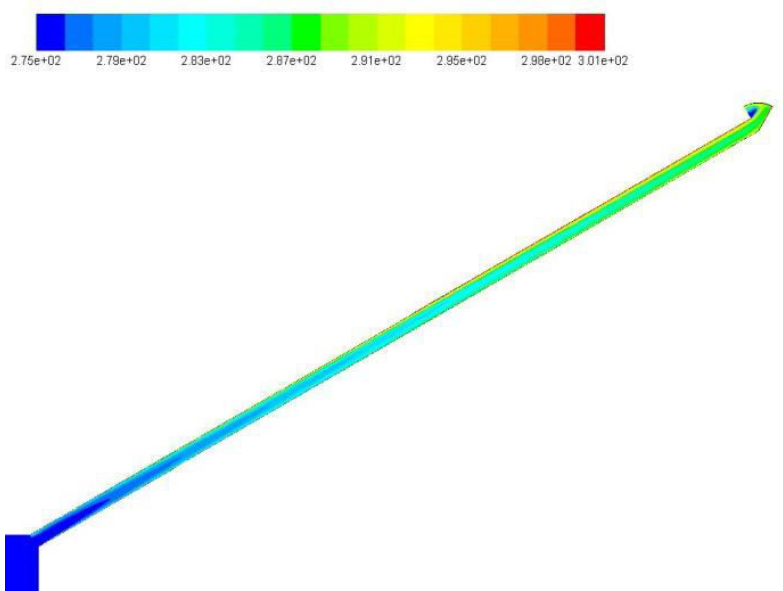

(b) Air temperature field.

Figure 20. Case 5: Air velocity and temperature fields in the ventilated channel. 
In winter regime, for Case 5, velocity values are higher near the outlet section of the channel because of the air heating, as shown in Figure 20(a), and the maximum value is equal about to 0.91 $\mathrm{m} / \mathrm{s}$. Temperature values grow in the ventilated channel with the distance from the inlet section, reaching the maximum on the top wall of the cavity, as shown in Figure 20(b), and it is equal to 301 K.
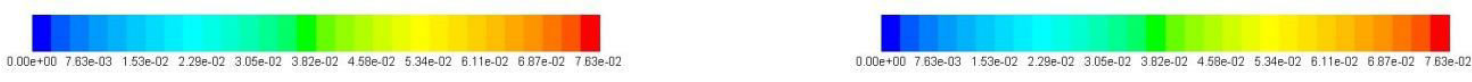

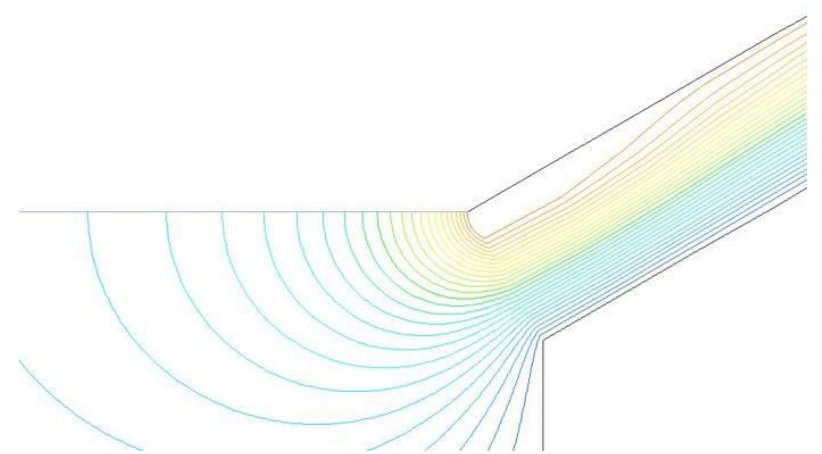

(a) Inlet section.

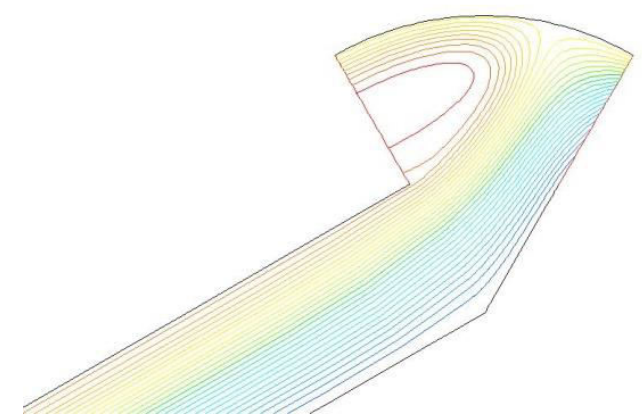

(b) Outlet section.

Figure 21. Case 5: Velocity stream functions at inlet and outlet sections of the channel.

Figure 21 and Figure 22 show, in particular, the inlet and the outlet sections of the ventilated channel. Velocity stream functions (Figure 21) underline that the fluid reaches the higher velocity values in the zone near the heated wall of the channel.

Velocity vectors show value increase near the inlet section of the channel in Figure 22(a). In proximity of the ridge, velocity vectors highlight a vortex and the maximum velocity value is obtained, as shown in Figure 22(b).

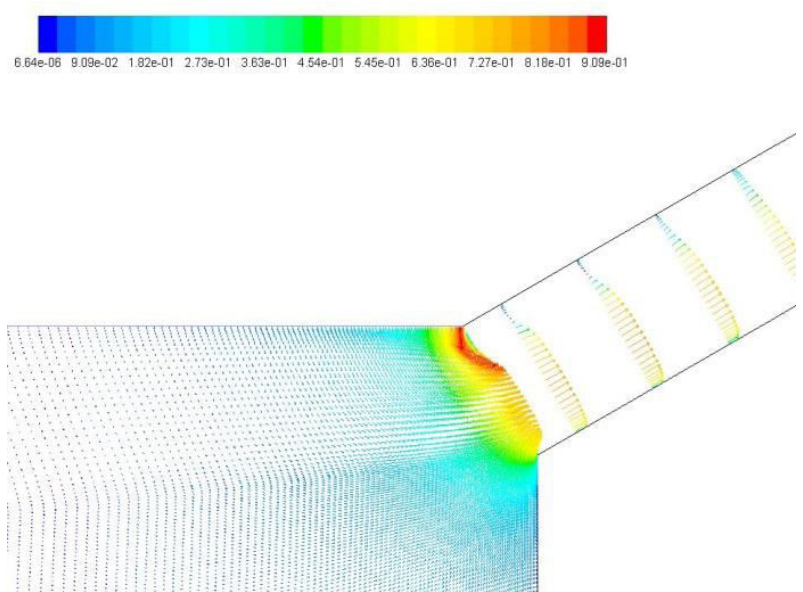

(a) Inlet section.

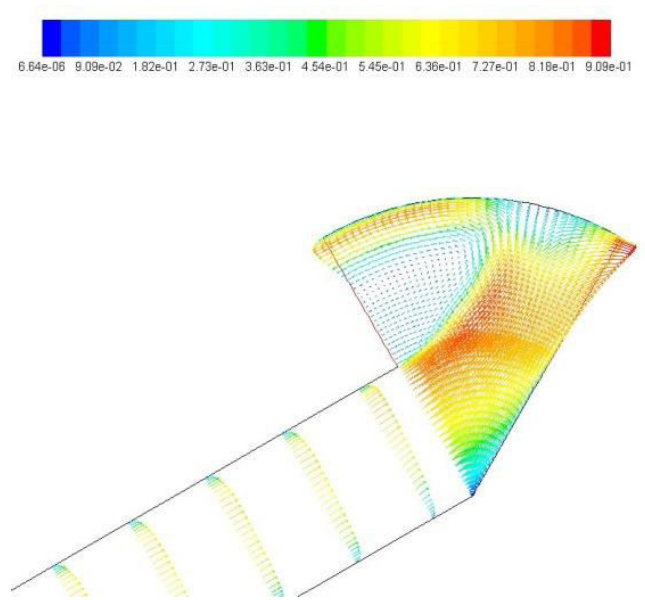

(b) Outlet section.

Figure 22. Case 5: Velocity vectors at inlet and outlet sections of the channel.

Figure 23(a) shows air velocity profiles of five channel cross sections, placed at $1.00 \mathrm{~m}, 2.00 \mathrm{~m}$, $3.00 \mathrm{~m}, 4.00 \mathrm{~m}$ and $5.00 \mathrm{~m}$ from the entrance of the ventilated channel. The effect of the heating is more evident near the hot top wall. The velocity value is maximum at $\mathrm{x}=5.0 \mathrm{~m}$ and it is equal to about $0.68 \mathrm{~m} / \mathrm{s}$.

Figure 23(b) shows air temperature profiles of five channel cross sections, placed at $1.00 \mathrm{~m}, 2.00 \mathrm{~m}$, $3.00 \mathrm{~m}, 4.00 \mathrm{~m}$ and $5.00 \mathrm{~m}$ from the entrance of the ventilated channel. Temperature values are 
lower in the central zone of the channel, whereas the radiative heat transfer grants the heating of the bottom wall of the channel.

Figure 23(c) shows air temperature profile of three longitudinal direction of the channel: the top wall, the bottom wall and the axis of the channel. All the profiles increase along the channel and for the top and the bottom walls temperature values increase mainly in the lower zone of the channel. In the central zone of the channel, temperature values increase about linearly. The temperature difference between the lower surface and the central section is equal to $7 \mathrm{~K}$. The temperature difference between the upper surface and the central section is about $15 \mathrm{~K}$. On the top line, the increment of temperature value is about $16 \mathrm{~K}$ near the exit section.

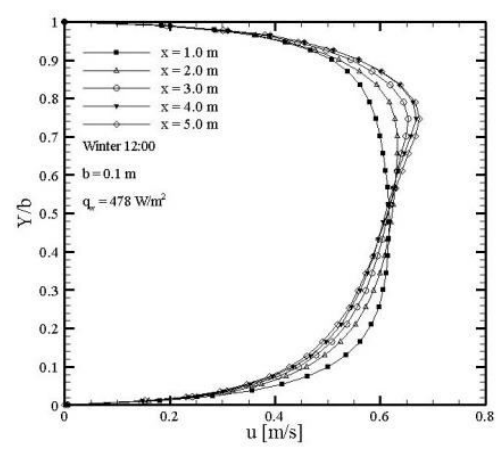

(a) Air velocity profile in cross sections.

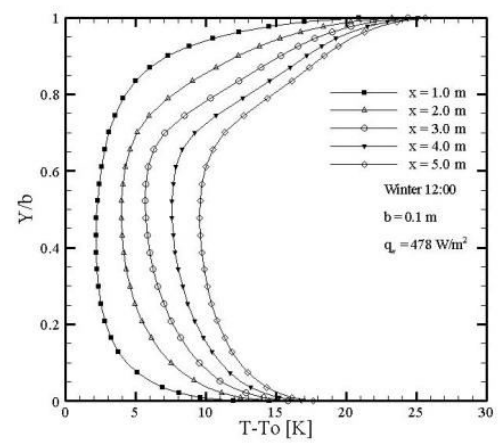

(b) Air temperature profile in cross sections.

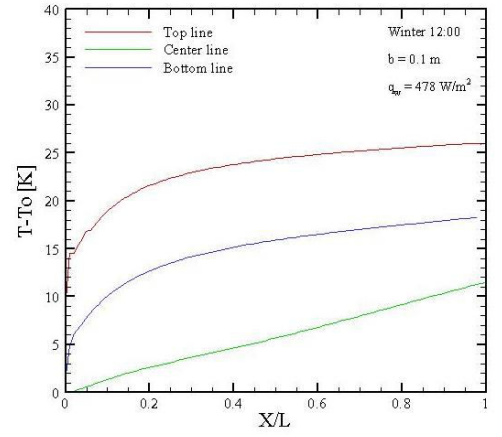

(c) Air temperature profile in the channel.

Figure 23. Case 5: Air velocity and temperature profiles in the ventilated channel.

In winter regime, for Case 6, velocity values are higher near the outlet section of the channel because of the air heating, as shown in Figure 24(a), and the maximum value is equal about to 0.74 $\mathrm{m} / \mathrm{s}$. Temperature values grow in the ventilated channel with the distance from the inlet section, reaching the maximum on the top wall of the cavity, as shown in Figure 24(b), and it is equal to 290 K.
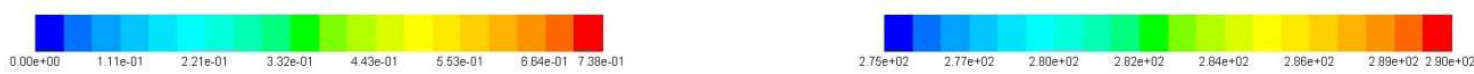

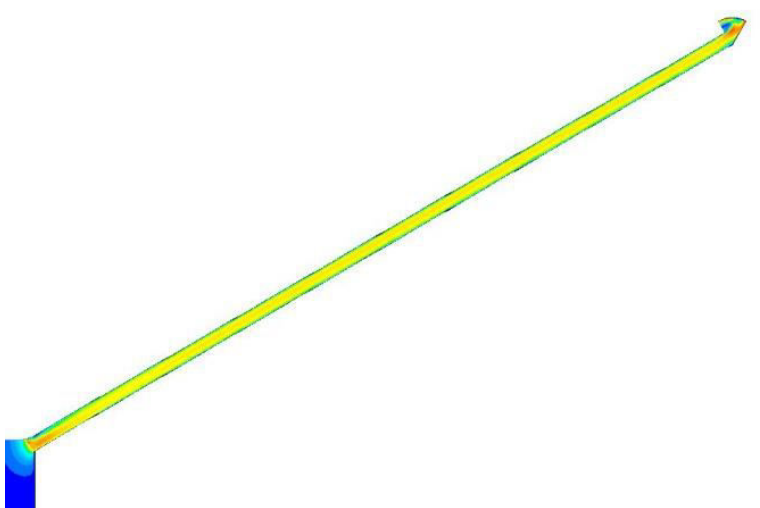

(a) Air velocity field.

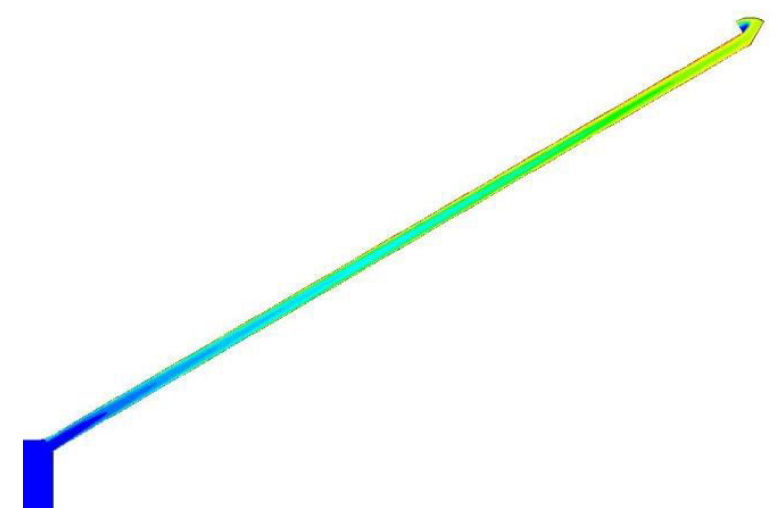

(b) Air temperature field.

Figure 24. Case 6: Air velocity and temperature fields in the ventilated channel.

Figure 25 and Figure 26 show, in particular, the inlet and the outlet sections of the ventilated channel. Velocity stream functions (Figure 25) underline that the fluid reaches the higher velocity values in the zone near the heated wall of the channel. 
Velocity vectors show value increase near the inlet section of the channel in Figure 26(a). In proximity of the ridge, velocity vectors highlight a vortex and the maximum velocity value is obtained, as shown in Figure 26(b).
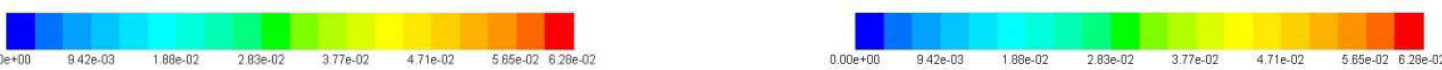

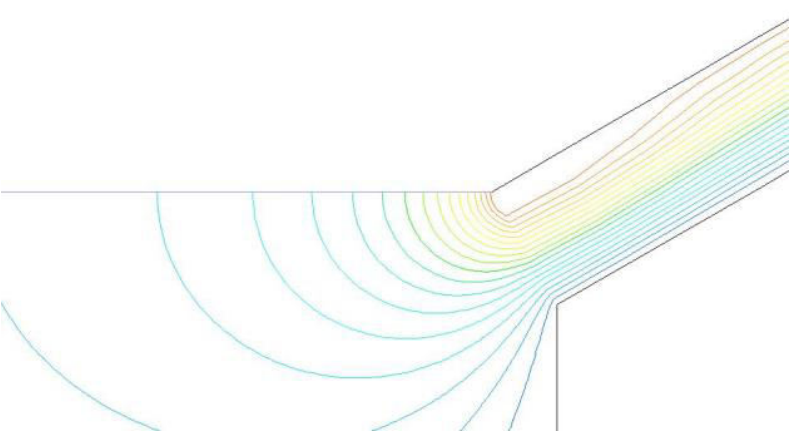

(a) Inlet section.

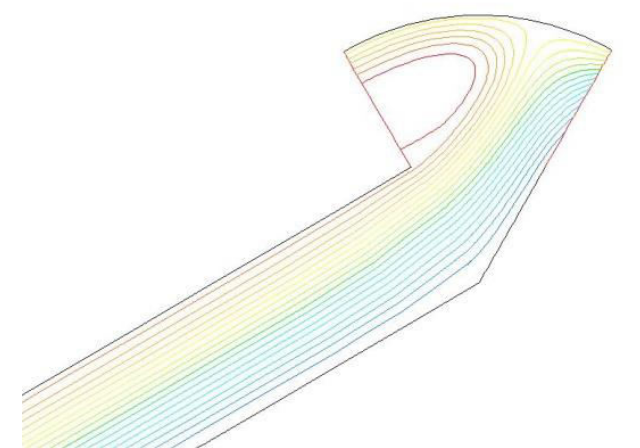

(b) Outlet section.

Figure 25. Case 6: Velocity stream functions at inlet and outlet sections of the channel.
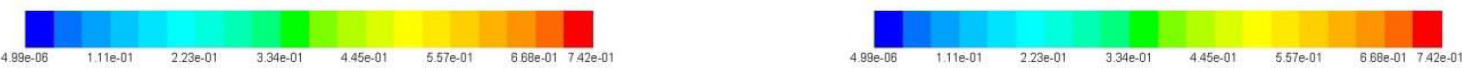

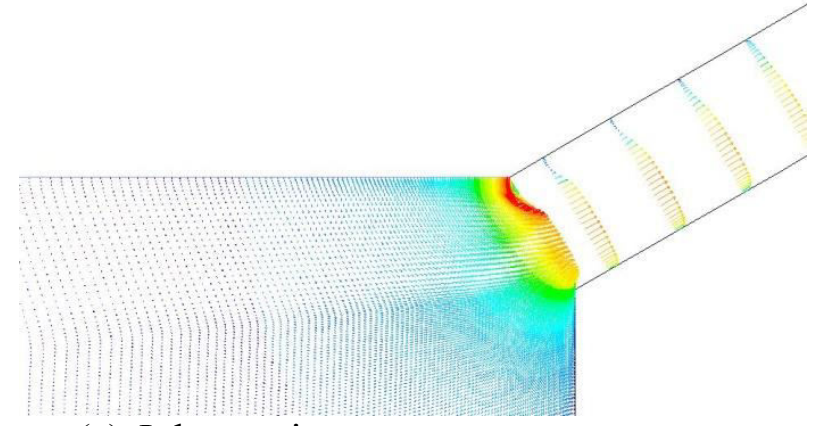

(a) Inlet section.

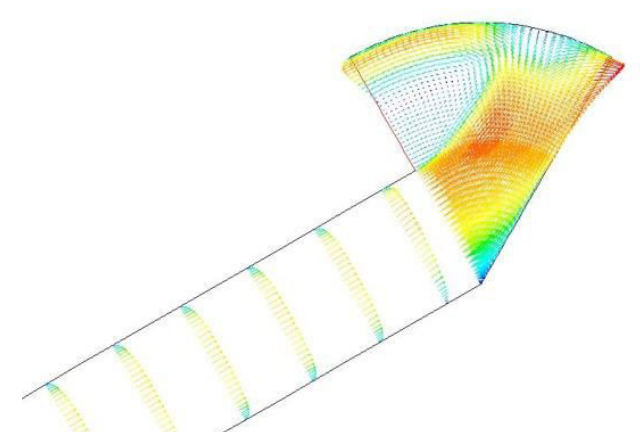

(b) Outlet section.

Figure 26. Case 5: Velocity vectors at inlet and outlet sections of the channel.

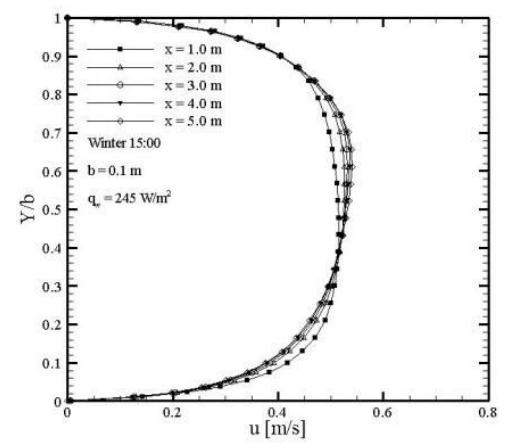

(a) Air velocity profile in cross sections.

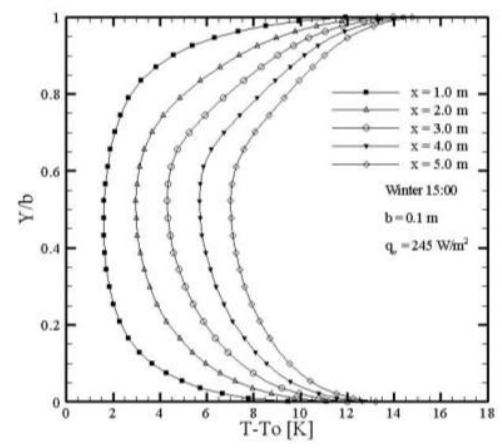

(b) Air temperature profile in cross sections.

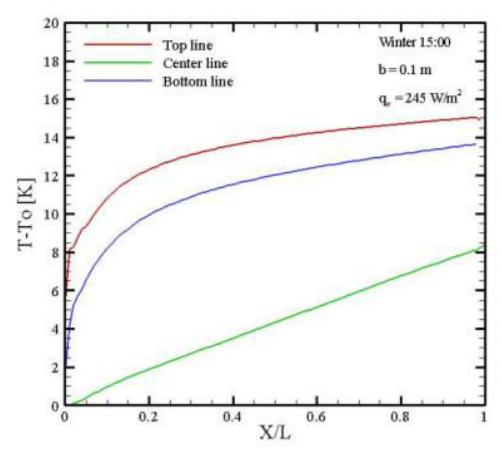

(c) Air temperature profile in the channel.

Figure 27. Case 6: Air velocity and temperature profiles in the ventilated channel. 
Figure 27(a) shows air velocity profiles of five channel cross sections, placed at $1.00 \mathrm{~m}, 2.00 \mathrm{~m}$, $3.00 \mathrm{~m}, 4.00 \mathrm{~m}$ and $5.00 \mathrm{~m}$ from the entrance of the ventilated channel. The effect of the heating is more evident near the hot top wall. The velocity value is maximum at $\mathrm{x}=5.0 \mathrm{~m}$ and it is equal to about $0.55 \mathrm{~m} / \mathrm{s}$.

Figure 27(b) shows air temperature profiles of five channel cross sections, placed at $1.00 \mathrm{~m}, 2.00 \mathrm{~m}$, $3.00 \mathrm{~m}, 4.00 \mathrm{~m}$ and $5.00 \mathrm{~m}$ from the entrance of the ventilated channel. Temperature values are lower in the central zone of the channel, whereas the radiative heat transfer grants the heating of the bottom wall of the channel.

Figure 27(c) shows air temperature profile of three longitudinal direction of the channel: the top wall, the bottom wall and the axis of the channel. All the profiles increase along the channel and for the top and the bottom walls temperature values increase mainly in the lower zone of the channel. In the central zone of the channel, temperature values increase about linearly. The temperature difference between the lower surface and the central section is equal to $6 \mathrm{~K}$. The temperature difference between the upper surface and the central section is about $7 \mathrm{~K}$. On the top line, the increment of temperature value is about $9 \mathrm{~K}$ near the exit section.

Finally, a comparison between summer cases and winter cases is reported, showing the velocity trend along the axis of the channel in summer and winter conditions. In Figure 28, velocity values decrease in the inlet section, then they rise reaching a lower value in the outlet section. In summer regime, values reach the maximum for the Case 2, when the heat flux is equal to $862 \mathrm{~W} / \mathrm{m}^{2}$, as shown in Figure 28(a). In winter regime, velocity values reach the minimum for the Case 6, when the heat flux is equal to $245 \mathrm{~W} / \mathrm{m}^{2}$, as shown in Figure $28(\mathrm{~b})$. When heat flux is smaller, values oscillations are less evident.

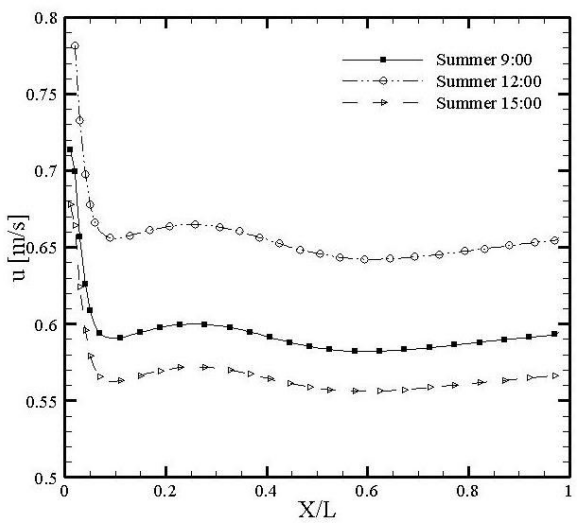

(a) Summer regime.

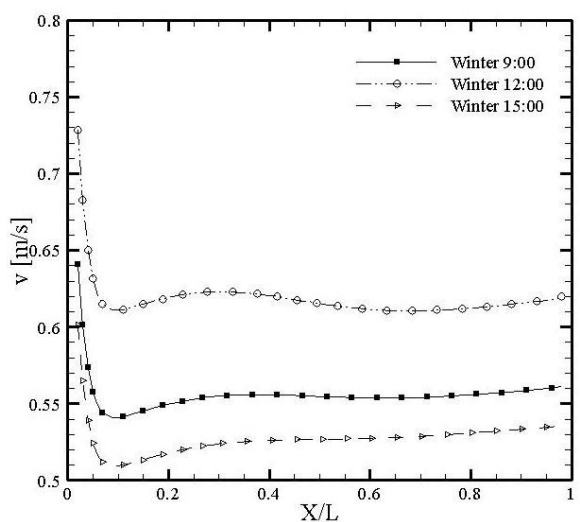

(b) Winter regime.

Figure 28. Air velocity profile in the ventilated channel.

Table 6

Thermofluidodynamic characteristics.

\begin{tabular}{|c|c|c|c|c|c|c|c|c|c|}
\hline Case & Season & $\begin{array}{c}\dot{q} \\
{\left[\mathrm{~W} / \mathrm{m}^{2}\right]}\end{array}$ & $\begin{array}{c}\mathrm{T}_{\text {inf }} \\
{[\mathrm{K}]}\end{array}$ & $\begin{array}{c}\dot{M} \\
{[\mathrm{~kg} / \mathrm{s}]}\end{array}$ & $\begin{array}{c}\mathrm{v}_{\text {avg }} \\
{[\mathrm{m} / \mathrm{s}]}\end{array}$ & $\begin{array}{c}\mathrm{v}_{\max } \\
{[\mathrm{m} / \mathrm{s}]}\end{array}$ & $\begin{array}{c}\mathrm{T}_{\text {avg }} \\
{[\mathrm{K}]}\end{array}$ & $\begin{array}{c}\mathrm{T}_{\text {havg }} \\
{[\mathrm{K}]}\end{array}$ & $\begin{array}{c}\mathrm{T}_{\max } \\
{[\mathrm{K}]}\end{array}$ \\
\hline 1 & Summer & 667 & 298 & 0.0647 & 0.528 & 0.884 & 314 & 328 & 330 \\
\hline 2 & Summer & 862 & 298 & 0.0721 & 0.589 & 0.986 & 317 & 335 & 338 \\
\hline 3 & Summer & 593 & 298 & 0.0615 & 0.502 & 0.840 & 313 & 325 & 327 \\
\hline 4 & Winter & 310 & 293 & 0.0615 & 0.484 & 0.791 & 286 & 291 & 293 \\
\hline 5 & Winter & 478 & 293 & 0.0698 & 0.549 & 0.908 & 289 & 298 & 301 \\
\hline 6 & Winter & 245 & 293 & 0.0577 & 0.455 & 0.738 & 285 & 288 & 290 \\
\hline
\end{tabular}


In Table 6, some thermofluidodynamic characteristics are described for each analyzed case. First of all, heat flux and the temperature on the bottom wall of the channel are reported. The mass flow rate $\dot{M}$ indicates the mass of air which passes in the ventilated channel per unit of time. $u_{\text {avg }}$ and $u_{\max }$ are, respectively, the average and the maximum values of the velocity in the ventilated channel. $T_{\text {avg }}$ is the average value of the temperature in the exit section of the channel. $T_{\text {havg }}$ is the average value of the temperature relative to the heated surface of the ventilated channel. $T_{\max }$ is the maximum value of the temperature in the channel.

\section{CONCLUSIONS}

A numerical study is realized to know the thermal behavior of a prototypal ventilated roof for residential use under variable solar radiation, to simulate summer and winter regimes. The system is composed by a single side of the roof and it consists of a ventilated cavity and two reservoirs. On the bottom wall of the ventilated channel, a constant value of temperature is applied to simulate optimal ambient condition in summer and winter periods. On the top wall of the channel, a heat flux is applied to simulate solar radiation operating at different hours on typical summer and winter days. In particular, six cases are analyzed: three in summer conditions and three in winter conditions. The study has reported that:

- Temperature rises in the channel with the distance to the inlet section due to the effect on heat transfer and flow air in the ventilated channel. The maximum value is reached on the top wall of the cavity. Case 2 and Case 5 show the maximum values in summer and winter conditions respectively.

- The air heating influences velocity values in the channel, so in summer period values are higher. Maximum values are reached in the outlet reservoir near the ridge, where a vortex increases velocity values.

- Temperature trend is the same along five different cross sections, but higher values are reached at $\mathrm{x}=5.0 \mathrm{~m}$ both in summer and winter regimes and maximum values are reached on the top wall of the ventilated cavity.

- Velocity trends along five different cross sections show that higher values are reached at $\mathrm{x}=$ $5.0 \mathrm{~m}$ both in summer and winter regimes and maximum values are reached near the top wall of the cavity.

- Along the channel, temperature trend grows in summer and winter condition, but values are higher in summer period, when the effect of solar radiation is more evident thanks to the convective effect within the channel. In winter, the effect of the ventilated layer is very important to reach optimal thermal and hygrometric conditions.

- The velocity trend along the axis of the channel in summer and winter conditions shows that values decrease in the inlet section, then they rise reaching a lower value in the outlet section. In summer regime, values reach the maximum for the Case 2. In winter regime, velocity values reach the minimum for the Case 6 . When heat flux is smaller, values oscillations are less evident.

\section{REFERENCES}

Banionis, K. et al. [2012], Impact of heat reflective coatings on heat flows through the ventilated roof with steel coatings, J. Civil End. Manag., Vol. 18, No. 4, pp. 505-511.

Bianco, V. et al. [2016], Thermal behavior evaluation of ventilated roof under variable solar radiation, Int. J. Heath Tech., Vol. 34, ppS346-S359.

Biwole, P.H. et al. [2008], Heat transfer in a double-skin roof ventilated by natural convection in summer time, Energ. Build., Vol. 40, pp. 1487-1497.

Çengel Y.A., Ghajar A.J. [2011], Heat and Mass Transfer, McGraw-Hill $4^{\text {th }}$ Ed, New York. 
Dimoudi, A. et al. [2006], Summer performance of ventilated roof component, Energ. and Build., Vol. 38, pp. 610-617.

Dimoudi, A. et al. [2006], Thermal performance of an innovative roof component, Renew. Energ., Vol. 31, pp. 2257-2271.

Gagliano, A. et al. [2012], Thermal performance of ventilated roofs during summer period, Energ. Build., Vol. 49, pp. 611-618.

Launder, B.E. and Spalding, D.B. [1974], The numerical computation of turbolent flow, Comput. Meth. Apll. Mech. Eng., Vol 3, pp. 269-289.

Lee, S. et al. [2009], An experimental study on airflow in the cavity of a ventilated roof, Build. Environ., Vol. 44, pp. 1431-1439.

Li, D. et al. [2016], Numerical analysis on thermal performance of naturally ventilated roofs with different influencing parameters, Sustain. City Soc., Vol. 22, pp. 86-93.

Manca, O. et al. 2014, Numerical investigation on thermal behaviors of an inclined ventilated roof. In: $12^{\text {th }}$ Biennal Conference on Engineering Systems Design and Analysis, 25-27 June 2014 Copenhagen, Denmark. ESDA2014

Ozdeniz, M.B. and Hancer, P. [2015], Suitable roof constructions for warm climates - Gazimagusa case, Energ. Buildings, Vol. 37, pp. 643-649.

Piva, S., et al. 2014, Summer thermal performance of ventilated roofs with tiled coverings. In: $34^{\text {th }}$ UIT Heat Transfer Conference, 1-4 July 2016, Ferrara, Italy.

Tong, S. and Li,H. [2014], An efficient model development and experimental study for the heat transfer in naturally ventilated inclined roofs, Build. Environ., Vol. 81, pp. 296-308.

Tong, S. et al. [2014], Thermal performance of concrete-based roofs in tropical climate, Energ. Build., Vol.76, pp. 392-401.

Villi, G. et al. [2009], CFD modelling and thermal performance analysis of a wooden ventilated roof structure, Build. Simul., Vol. 2, pp. 215-228.

ANSYS-Fluent Inc. Ansys-Fluent 12.2 manuals. Ansys ed. 2012.

Fluent-Inc. Gambit 2.4 Modeling Guide ed. 2007. 